EXPERIENTIAL LEARNING IN HOSPITALITY MANAGEMENT: AN

EXPLORATION OF THE KNOWLEDGE, SKILLS AND ABILITIES

ACHIEVED IN A HOSPITALITY MANAGEMENT PROGRAM INTERNSHIP

A Dissertation
presented to
the Faculty of the Graduate School
at the University of Missouri-Columbia
In Partial Fulfillment
of the Requirements for the Degree
Doctor of Education
BUANTELLA ANDERSON-NOTO
Dr. Paul Watkins, Dissertation Supervisor

DECEMBER, 2013 
The undersigned, appointed by the dean of the Graduate School, have examined the dissertation entitled

\section{EXPERIENTIAL LEARNING IN HOSPITALITIY MANAGEMENT: AN EXPLORATION OF THE KNOWLEDGE, SKILLS AND ABILITIES ACHIEVED IN A HOSPITALITY MANAGEMENT PROGRAM INTERNSHIP}

Presented by Quantella Anderson-Noto

A candidate for the degree of Doctor of Education

And hereby certify that, in their opinion, it is worthy of acceptance.

Dr. Paul Watkins

Dr. William Bratberg

Dr. Lisa Bertrand

Dr. Ruth Ann Roberts 


\section{ACKNOWLEDGEMENTS}

It is with sincere appreciation and thanks that I acknowledge the many individuals that provided me with guidance and inspiration during my journey to the completion of my research.

I am deeply indebted to the chair of my committee, Dr. Paul Watkins, for his support of my research, his leadership, patience, guidance, and ability to keep the edits and revisions coming back to me at such a rapid pace that I could never escape the process; Dr. Bill Bratberg for reminding me that the best dissertation is a completed dissertation, and he seemed to remind me just when I needed it; Dr. Ruth Roberts who taught me a great deal about education and leadership, as well as helped me clearly understand what epistemology means; and Dr. Lisa Bertrand who was first to ask to join my committee and who recruited me into this process by telling me that I should, and could, do this. She was right.

I am grateful to the people in my life that sacrificed my time and attention to complete my journey. To my mother, Lula Collins, who taught me to plan my work and work my plan; my children, Kirkland and Kyle, who always expressed their awe and pride at my commitment and waited patiently for me to finish so they could have their old mom back, and enjoy the new one. And last, I would like to acknowledge and thank my husband, Brian, for the countless days and nights of love and support during my journey. He served as my research assistant, editor, critic, encourager and friend and was always in my corner when I was ready to throw in the towel. I could not have done it without them. 
ACKNOWLEDGEMENTS

\section{Chapter}

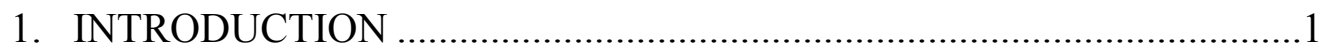

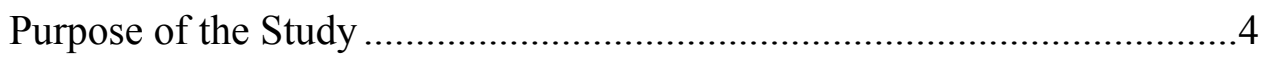

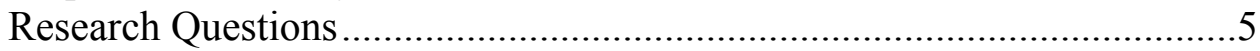

Conceptual Framework .........................................................................6

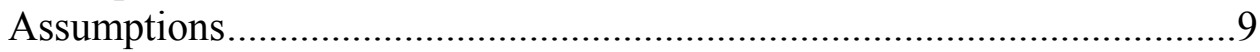

Definition of Terms............................................................................

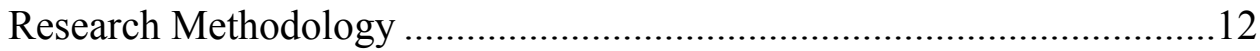

Anticipated Outcomes..........................................................................13

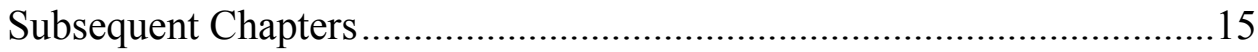

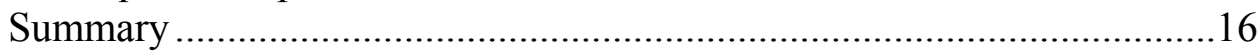

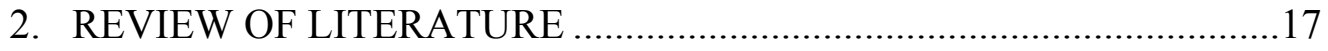

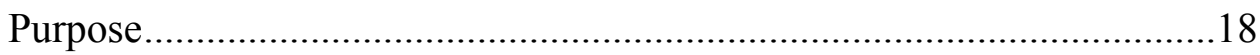



Social Construct of Learning ................................................................21

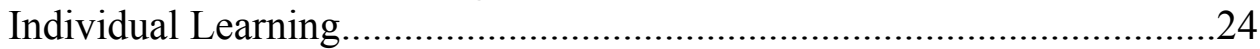

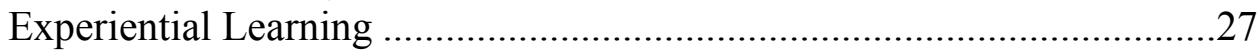

Internships as Experiential Learning .......................................................30

Internships and Leadership Development..................................................34

Leadership Competency Models ...............................................................38

Hospitality Education and Leadership Competency...................................39

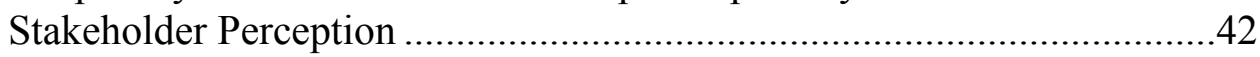

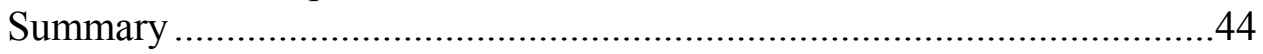

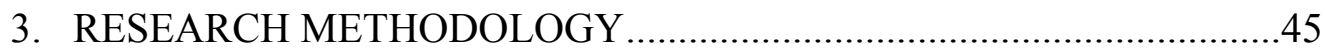

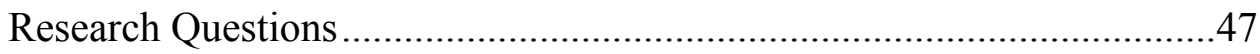



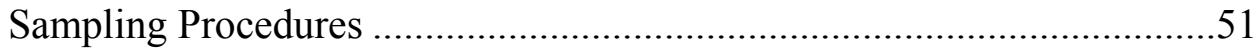

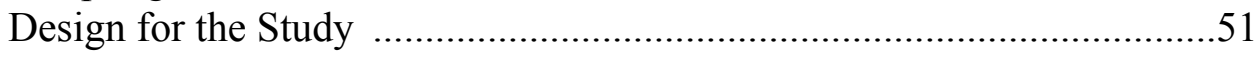

Rationale for the Research Design......................................................52

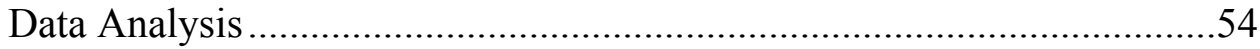

Data Collection Methods and Procedures................................................54

Data Analysis Procedures ...................................................................56






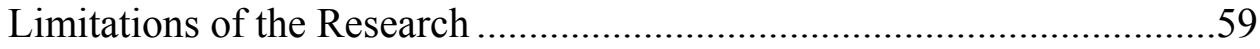

Description of the Researcher................................................................60

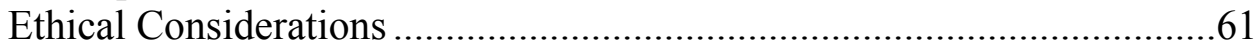

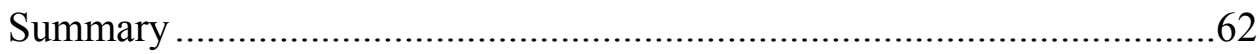

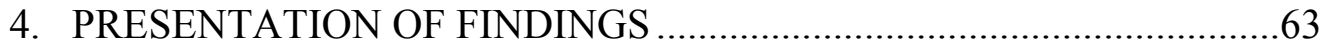

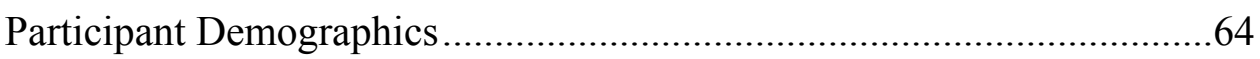

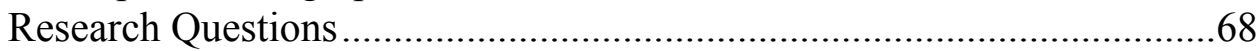

Five Major Findings Emerged from the Study ........................................69

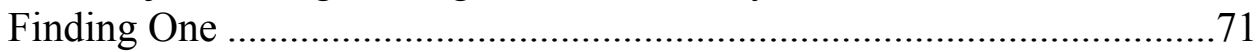

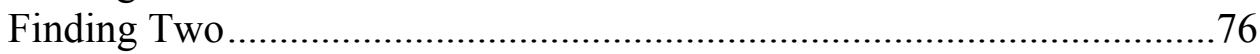

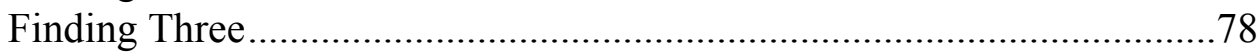

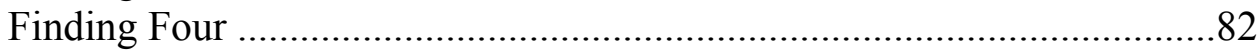

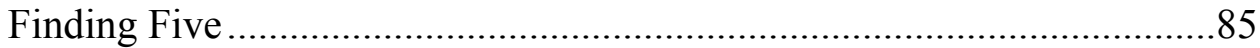

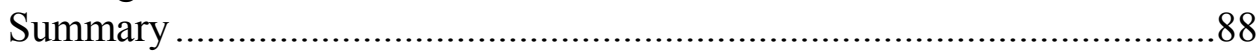

5. ANALYSIS, INTERPRETATION, FINDINGS, CONCLUSION AND RECOMMENDATIONS.......................................90

Analytical Category 1: Gains and Gaps in Developing Hospitality Management Leadership Competencies .............................................92

Analytical Category 2: Interpersonal Skill Development and

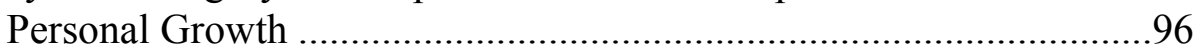

Analytical Category 3: Supervisor's Perceptions and Evaluations ............99

Assumptions from Chapter One...........................................................101

Summary of Interpretation \& Findings.................................................102

Conclusions and Recommendations ....................................................104

Perceptions that Leadership Skills were gained but Gaps Remain...........104

Interpersonal Skills were Gained ...........................................................105

Personal Growth and Change ……………………….........................106

Supervisor Perceptions of Leadership Competencies .............................107

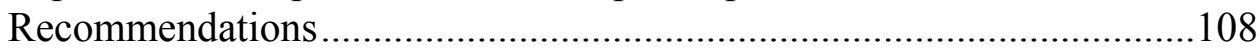

Recommendations for Hospitality Management Interns .........................108

Recommendations for Hospitality Management Internship

Advisors and Faculty ......................................................................109

Recommendations for Hospitality Management Industry

Internship Supervisors .........................................................110

Recommendations for Future Research ................................................111

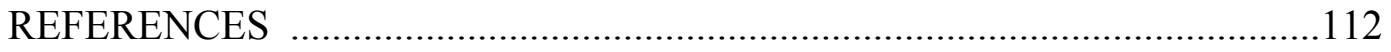


APPENDIX A: INSTITUTIONAL REVIEW BOARD (IRB) LETTER OF


APPENDIX B: INSTITUTIONAL REVIEW BOARD (IRB) LETTER OF

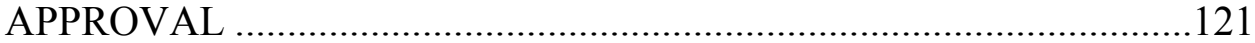
APPENDIX C: SUBJECT INFORMED CONSENT LETTER ................122

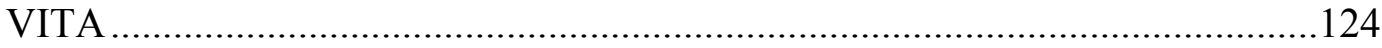




\section{Chapter - I}

Introduction

The American Hotel and Lodging Industry released the "coffee-table" book titled “A Century of Hospitality, 1910-2010" to commemorate its 100-year anniversary (Vermillion, L., 2010, p. 4). The book highlights the changes and growth that occurred in the tourism and hospitality industry over the last century. The hospitality and tourism industry is currently a multi-billion dollar industry, among the nation's largest services export industry and one of America's largest employers (2011 Lodging Industry Profile, http:// www.ahla.com). In 2011, 98 million jobs were directly created in the travel \& tourism industry worldwide and, by 2022, the industry is expected to directly generate 120 million jobs with total employment world wide projected at 328 million jobs (Economic Impact of Travel \& Tourism Summary 2012, retrieved May 25, 2012, http:// wttc.org).

To maintain a competitive advantage in a global environment, the hospitality industry will need future leaders that have the competencies and skills necessary to adapt to a changing industry. In this increasingly complex industry, senior leadership matters and identifying the most critical skills and competencies related to highperforming leaders is crucial (Brownell, 2007). To better facilitate the process of identifying important leadership skills, hospitality industry managers and leaders have begun to use competency models as a tool to identify the crucial knowledge, skills and abilities (KSAs) that hospitality leaders will need for success. The focus of competency models is behavior of the individual rather than personality, which may 
be more difficult to measure. Competency models are used by organizations to help identify the behavior needed to perform effectively and successfully and are a common language for discussing capabilities and performance. Identifying the relevant competencies for industry professionals not only assists with developing future leaders, but the process also helps combat the challenges in the recruitment and selection, training and career development, and change management in an organization (Chung-Herrera, Enz, \& Lankau, 2003). The competencies that are critical for hospitality leaders vary among divisions (lodging, food service, travel, and tourism) yet share a common set of essential competencies for entry-level managers to senior-level leadership.

The concept of knowledge, skills and abilities (KSA's) focuses on the "core business factors" that research-based information has found to be the leadership competencies that serves as the foundation for job descriptions, management training and job performance appraisals in the hospitality industry (Kay \& Moncarz, 2004, p. 286). Many of the identifiable KSAs can be grouped in "leadership" and "interpersonal" categories, with numerous skills and abilities within those categories. Some of the key knowledge, skills and abilities identified include: human resource management, information technology, financial management, critical thinking, and communication, leadership, marketing skills, time management and industry knowledge (Kay \& Moncarz, 2004).

Over the years the hospitality industry has realized an increased need for a "leadership style" in managers versus a "control style", with an emphasis on strategic and corporate skills instead of operational and technical skills (Umbriet, 1993; 
Raybould \& Wilkins, 2006). Numerous studies conducted in the 80 s and 90 s on the competencies deemed essential for hotel leaders indicated that "leadership" and "interpersonal" competencies, though broad, ranked highest among the most desirable skills for developing ones leadership style (Johanson, Ghiselli, Shea, \& Roberts, 2011).

Central to the evolution of the industry is the role that hospitality education has played in the advancement of the industry. Specialized hospitality management programs have dated back to the 1920s, when Cornell University started the first hospitality management program, to today, where there are over 200 four-year institutions preparing students to enter the hospitality workforce (Annaraud, 2006). Since the 1920s hospitality educators have leaned on industry leaders for guidance regarding the essential competencies required of graduates for success (Kay \& Russette, 2000) and hospitality management programs have made significant curricular changes to meet the industry's perceived evolving needs (Pavesic, 1991). These programs have begun to play a role in developing many of the desired competencies in students and have done so by integrating experiential learning requirements into the academic curriculum. Experiential learning can take several forms - internships, service learning and practicum's - and is believed to be essential to a quality business education.

Hospitality management students who participated in an experiential learning program, as compared to those that did not, had a better understanding of how hospitality organization's function, had an increased ability to adapt to change, and demonstrated improved leadership and financial management skills (Lee, 2007). 
Integral to developing leadership competencies is the ability to understand how interns learn, and particularly how they shape learning in an experiential learning environment. This study will seek to understand the perceptions that interns have regarding their leadership skills and competencies before and after their experiential learning experience, as well as discuss the perceptions of the supervisor or manager of the intern's skill development. The perspective of the stakeholders involved in the experiential learning process - interns and supervisors or mentors - will assist in furthering the process of developing leadership competencies.

\section{Purpose of the Study}

The goal of this research is to gain more knowledge regarding the relationship between experiential learning, or internships, and the achievement of leadership competencies. According to the National Association of Colleges and Employers (NACE) 2010 Employer Internship Survey, 83.4\% of employers surveyed said that internship programs help the organization recruit entry-level college graduates (Internship Programs Feed Full-Time Hiring. In Spotlight Online for Employment and Recruiting Professionals, April 28, 2010, http://www.naceweb.org). The survey also found a correlation between participating in an internship and staying on the job. Similarly, the NACE 2010 Student Survey found that new graduates who participated in an internship were more likely to receive a job offer than peers who did not participate in an internship. Learning can take many forms, and an internship is one form of active learning (Solnet, Kralj, Kay \& DeVeau, 2009). This type of work-integrated learning provides participants with the ability to develop specific leadership competencies and 
skills used by effective leaders. John Lechleiter, president and COO of Eli Lilly and Company, says that the model for leadership development comes from "job experience integrated with classroom instruction and leadership activities such as coaching and mentoring" (How Top Companies Breed Stars, October, 2007, http://www.cnnmoney.com).

\section{Research Questions}

An objective of a research question is to "operationalize" the proposed research (Mertens, 2005, p. 344). This study will be used to gain a greater understanding of the competencies that interns gain during their experiential learning experience and their perception of the competencies gained. In order to deliver high-quality, industry-relevant education, hospitality management educators must continually identify and investigate current and evolving competencies for future managers and leaders (Kay \& Russette, 2000). This study will address the following questions:

1. How do interns perceive their growth as a leader during their hospitality management internship experience?

2. What are the interns' perceptions of their communication skills?

3. What are the interns' perceptions of their interpersonal skills?

4. What are the interns' perceptions of their financial management skills?

5. What are the interns' perceptions of their information technology skills?

6. What are the interns' perceptions of their marketing skills?

7. What are the supervisor's perceptions of the leadership competencies and knowledge gained by interns during the internship experience? 
Addressing those questions will provide a framework for exploring experiential learning in the workplace and the information gathered will be used to gain a greater understanding of the competencies interns gained during their experience.

\section{Conceptual Framework}

The conceptual framework for this study is the exploration of experiential learning through a social exchange that promotes student understanding of leadership within the context of hospitality management. The experiential learning is achieved through the completion of an internship by the students within a hospitality management program. Interns are particularly interesting to study because they operate at two different crossroads: in the workplace, where they are expected to be competent workers and partners in productive activity, and in school, where they are learners in need of new knowledge (Moore, 2007). Conventional learning methods may have ignored the learning process that takes place between students in a work experience and particularly those who are new to an industry. A learning structure that takes into account interests and experiences of the student, as well as delivers knowledge, strikes a balance (Dewey, 1938). The experiential learning process allows the intern to draw the connection between the workplace and the learning process, and to strike a balance between the two.

Leadership, according to Grint (2000) is essentially a social phenomenon; leaders must construct an imaginary community that followers want to join. Ford and Lawler (2007) examines the social construction of leadership and suggests that it "requires us to consider how relationships are described and understood by the individuals involved, using their own language and conversation" (p. 419). The 
experiential learning process in this study provides a social construct for the interns to define and observe leadership and gain leadership attributes and skills. Few people have a clear definition and understanding of leadership. This is particularly the case with young students who have not had any formal training in leadership (Maxwell \& Greenhalgh, 2011, p. 107). Billsberry (2009) adopts a socially constructed approach to leadership education. According to Billsberry, a socially constructed theory of leadership education avoids problems such as disagreements about definitions and offers instructors an opportunity to align theory with pedagogical practice. When students become observers of leadership in action, and have the opportunity to practice through experiential learning, they can then interpret and assess leadership. The pedagogical application of leadership education provides for the use of a variety of teaching methods to allow students to define their own understanding of leadership, such as experiential learning, or internship programs. A socially constructed approach to leadership is based on people's perception - it is in the eye of the beholder. Not what you want it to be, but what powerful voices make it (Billsberry, p. 3).

One social constructivist approach to experiential learning is "curriculum at work". This is the idea of curriculum as a component of workplace learning. The term curriculum from this perspective means "examining the social and technical means by which activities get accomplished: What one needs to know, and how one needs to think in order to do the work (Moore, 2004, p. 329). The situation cognition theorists maintain that "people learn particular kinds of knowledge and skill better and more deeply when they actually have to use it in the performance of work" (Moore, p. 331). Several factors can shape the participants workplace learning experience: internal features of the 
organization, personal features of the participants and the external environment. The specific workplace environment common to the interns in a hospitality management program is working in the service industry. The hospitality industry is a service-based, versus manufacturing-based, industry. To maintain a competitive advantage, the service industry, and by definition the hospitality industry, must maintain high productivity levels for competitive survival.

The qualitative approach to analysis that will be used is case study research. A case study is "an intensive description and analysis of a bounded social phenomenon, or multiple bounded phenomena, such as a program or a process" (Bloomberg \& Volpe, 2012, p. 31). The nature of this research fits the case study format, specifically a collective case study, as the study involves multiple interns providing their perception of the internship experience within a specific hospitality management program. Case study research involves a detailed description of a setting and its' participants, accompanied by an analysis of data for themes, patterns and issues (Merriam et. al, 1998). Case study research is distinguished by the size of the bounded case (Creswell, 2007, p. 74) and the research is bounded by the number of students, time and place. One of the implications of multiple realities is that the research questions may change s the study evolves and the progresses. The questions may be shaped by the background of the participants and the context under which they are participating.

Case study research was chosen because it will allow for cross-case analysis. As detailed descriptions of themes within each case emerge, this form of research will provide for "with-in" case analysis and "cross-case analysis" (Bloomberg \& Volpe, p. 31). Thematic analysis allows the researcher to understand the complexity of the cases 
and to not generalize the research but rather have a goal of transferability. Transferability will allow the researcher to understand how, if at all, the knowledge can be applied to similar contexts and the likely applicability of findings to other situations under similar, but not identical, conditions (Patton, 1990).

Almost all hospitality and tourism programs include either as mandatory or as an elective, an internship (Zopiatis \& Constanti, 2012, p. 44). However, Lam and Chang's study (as cited in Zopiatis and Constanti) inform us that interns' expectations still may not be met. Alpert et al., (2007) and Walo (2001) emphasized the need for clarity of internship goals and to review if the internship is meaningful to the major stakeholders - the interns and the host organization. As a result of this research, we may gain more insight as to how to create a more meaningful experience for the interns. We may also better understand the construct of knowledge through the eyes of the interns and explore how the experiential learning environment impacted their perspective of leadership in the hospitality industry.

\section{Assumptions}

There are several assumptions that will be considered regarding the approach to this study. As learning may be considered to be the enactment of permanent change within an individual (George, 1999), one assumption is that the interns will be different at the completion of their internship from their program introduction. As the interns participate in several learning activities that are designed to integrate their knowledge with the newly gained experience, the experiential learning loop of knowledge, 
experience and self-reflection may yield a change in the intern's personal and professional awareness and development (Tesone, 2004).

Another assumption of this research is that the supervisors and mentors that participate in the experiential learning program are competent in their ability to evaluate the interns in a meaningful way and give relative feedback. The supervisors at the organizations chosen by the interns for participation should be able to effectively design, coordinate and supervise a meaningful experiential learning program. It is assumed that the supervisors are aware of the range of competencies that the intern is trying to achieve, and the supervisor should be able to effectively guide the intern, and properly evaluate the competencies gained.

\section{Definition of Terms}

\section{$\underline{\text { Hospitality Management }}$}

The word hospitality means "the reception and entertainment of guests, visitors or strangers with liberality and good will" (Oxford English Dictionary) and historically referred to institutions that provide shelter, food, or both, to people away from their homes. The term refers to the range of occupations and professional practices associated with the administration of hotels, resorts and other lodging facilities, foodservice, travel and tourism, meetings and special events.

\section{Experiential Learning}

Various terms have been used to define experiential learning. Kolb (1984) states that "Learning is the process whereby knowledge is created through the transformation of experience. Knowledge results from the combination of grasping 
experience and transforming it” (p. 41). Hoover and Whitehead (1975) provides the following definition: Experiential learning exists when a personally responsible participant cognitively, affectively, and behaviorally processes knowledge, skills and/or attitudes in a learning situation characterized by a high level of active involvement ( $\mathrm{p}$. 25). The experiential learning component can take on many forms, including internships, practicums, distance-learning, and service projects (Clark \& Webb-White, 2010, p. 110). Internship

An internship is a form of experiential learning that integrates knowledge and theory learned in the classroom with practical application and skills development in a professional setting. Internships give students the opportunity to gain valuable applied experience and make connections in professional fields they are considering for career paths and give employers the opportunity to guide and evaluate talent (NACE Position Statement on Internships, 2011). An internship is a program designed to provide an experiential learning experience whereby students acquire knowledge and skills in their chosen field of study (Southeast Missouri State University Hospitality Management Internship Policies \& Procedures, 2012). Knowledge, Skills and Abilities (KSA)

Knowledge, skills and abilities are desirable attributes for current and future managers for success in hospitality management. Kay and Moncarz (2004) propose that the KSA's that are most important for management success are divided into four domains, with additional areas for development in each domain. The four main domains are human resource management, marketing, financial management and information technology. 


\section{Research Methodology}

The best research method to gain an understanding of the questions posed is a qualitative research method. As Merriam (1998) states, qualitative research is "designed to inductively build rather than to test concepts, hypotheses and theories" (p. 45), and this study will build upon the concept that experiential learning is a way for students to achieve skills that are valuable to the continuing success of the hospitality industry. The prominent characteristics of qualitative research design include: the ability to gain more in depth information that may be difficult to convey quantitatively; the ability to use natural settings as the source of data; and qualitative research has an "emergent" nature, as opposed to a predetermined design (Hoepfl, 997). For practical purposes, the qualitative approach is wise because no valid, appropriate quantitative methods seem feasible to measure the outcomes achieved in the experiential learning process or to measure the reflection provided by the individual participants (Mertens, 2005).

The qualitative approach best suited for this study is constructivism. Lincoln and Guba (2000) identified three questions that help define a paradigm - ontological, epistemological, and methodological - and constructivist researchers use this paradigm as a way to interpret the meaning of something from a certain situation or individual standpoint (Mertens, p. 9). According to constructivists approach, the goal of research is to understand the multiple social constructions of knowledge, and this research will explore the knowledge gained from multiple participants in various knowledge-based constructs.

The constructivist approach reflects upon the basic tenet that reality is socially constructed by people active in the research. Multiple qualitative data collection 
strategies are used in developing the findings of constructivist research. The

constructivist uses more personal and interactive modes of data collection, such as interviews, observations, and document reviews (Mertens, p.15).

The specific research inquiry that will best unfold each experience is case study. Case study research is both a methodology (a type of design in qualitative research) and an object of study (Creswell, 2007). They type of case study is distinguished by the size of the bounded cases. This research will be a collective case study whereby several cases will be used to illustrate interns' perceptions of the leadership competencies gained during an experiential learning and social exchange experience. Case study analysis can be "holistic" (analysis of the entire case) or "embedded" (analysis of specific aspects of the case). This research will utilize embedded analysis which will allow the researcher to analyze parts of the case specific to the research questions presented (Creswell, 2007).

The data collected for this study will be consistent with qualitative data collection methods. The data collected for this study will be in the form of in-depth interviews, critical incident reports obtained through observations and formal evaluations provided by the internship supervisor.

\section{Anticipated Outcomes}

Increasingly hospitality management programs have required experiential learning participation for students to enhance their leadership skills by achieving more competencies through workplace learning. In that regard, there are several outcomes that can be anticipated from this study. 
One outcome of this study is that it may inform individuals who direct internship programs on the theory and practices behind the concept of experiential learning and internships. The study may provide insight into the perceptions of learning that occurs in the experiential learning environment and if students are able to integrate their classroom knowledge to the workplace. This study may also provide educators with information that assist in designing and implementing hospitality management internship programs as well as tools on how to prepare students as future leaders in the industry, helping bridge the leadership deficit that exists.

This research may also further validate the concept that the competency model is a beneficial tool that may help identify the KSAs that students are achieving. The evaluation by employers of the competencies achieved may yield information about what areas students excel in their achievement of competencies and where there are still opportunities for growth. It is also anticipated that the triangulation of the data will provide a positive correlation between the participants in the internship and the outcomes achieved.

The question of how well students perceive the hospitality industry competencies, standards, and their achievements, will provide an understanding of how the experience impacted them individually. The students may perceive the competencies as realistic, operational and achievable, and thus, may believe that they can realize career success. The data may also indicate that a number of the students had mixed or negative feelings about the experience and what was learned, which is an outcome that can lead to more questions about variables and other factors that may impact those perceptions. Their reflection on the experience will help to understand how significantly an internship 
can change their lives and help them gain the knowledge that they will need to become leaders of the future.

Finally, the outcomes of this study may help identify areas where future research may benefit. More research may be needed on how experiential learning can be best integrated into hospitality management programs and how effective these programs are in impacting the overall academic curriculum.

\section{Subsequent Chapters}

This research will seek to understand the factors that impact learning in the workplace, evaluate the competencies that the students gained during their experience, and gain an understanding of students' perceptions of and reflection on the skills and competencies required for the hospitality industry. The subsequent chapters in this study will further explore these research questions. The second chapter of this study will provide a review of the literature that provides the foundation for understanding adult learning and the experiential learning process. The literature review will also address the rise of competency models and KSAs in organizations and how the hospitality industry has identified and embraced skills that are detrimental to the success of the industry. The methodology of the study will be presented in chapter three. The sample size, instrumentation for the research and rationalization for using the instruments chosen will be discussed, as well as address issues of quality regarding the reliability and validity of the data. The description and analysis of data will be presented in chapter four, and chapter five will summarize the findings, provide a conclusion, address implications for the hospitality industry and make recommendations for future research. 


\section{Summary}

What are the characteristics and competencies required by hospitality industry professionals to maintain the competitive advantage? Identifying appropriate competencies helps senior managers in selecting, developing and coaching future leaders, as well as mapping career paths and planning management succession (Chung-Herrera, Enz and Lankau, 2003, p. 17). Preparing for the future will include identifying the competencies of students in hospitality management programs in higher education and designing experiential learning programs that will create competent, effective, and strategic leaders of the future. The goal of this research is to gain more knowledge regarding the relationship between experiential learning, or internships, and the achievement of leadership competencies. This study will seek to understand the perceptions that interns have regarding their leadership skills and competencies before and after their experiential learning experience, as well as discuss their perceptions of the supervisor or manager of the internship experience. 


\section{Chapter II}

\section{Review of Literature}

The changing nature of the hospitality industry suggests that new skills are required of current and future hospitality industry leaders. Identifying and developing leadership talent able to assume leadership positions can be a powerful competitive advantage (Brownell, 2007). The industry has rapidly embraced and implemented new business models and, subsequently, realized that strong leadership skills are needed in a global and diverse economy (Kay \& Moncarz p. 286).

Over the years the hospitality industry has realized an increased need for a "leadership style" versus a "control style" in managers, with an emphasis on strategic and corporate skills instead of operational and technical skills (Umbriet, 1993; Raybould \& Wilkins, 2006). Research has demonstrated that a manager's leadership style has a tremendous influence on employees' behavior, including adopting the organizations strategic and marketing initiatives (Clark, Hartline \& Jones, 2009, p. 210).

The questions for exploration in this study concern the knowledge, skills, and abilities, or competencies, needed by hospitality management students to develop a leadership style that prepares them for success. Human-resource related skills, such as training and motivating, were believed to be the most important skill set for hospitality management. Over time, three fundamental skills essential for any manager were introduced; technical, human, and conceptual (Katz, 1955). Technical skill involves an understanding of, and proficiency in, a specific type of activity, a skill that requires specialized knowledge. Human, or interpersonal skill, requires effective communication 
and involves working with people and understanding their behavior. Conceptual skill is the ability to view an organization as a whole as well as the ability to understand the organization within its environment (Gregoire, 2010, p. 278). Changes in the business environment over the years shifted to a need for additional skills associated with leadership such as financial management, information technology and marketing skills. The implication is that the knowledge, skills, and abilities needed by managers and leaders have changed through the years (Kay \& Moncarz, p. 286).

The changes may also suggest that there is not a consensus on one set of core competencies that the industry has agreed upon, but the ideal variety of skills may depend upon the variables in the individual's environment. Integral to developing leadership competencies is the ability to understand how interns learn, and particularly how they shape learning in an experiential learning environment. This study will seek to understand the perceptions that interns have regarding their leadership skills and competencies before and after their experiential learning experience, as well as discuss their perceptions of the supervisor of the internship location.

\section{Purpose}

The goal of this research is to gain more knowledge regarding the relationship between experiential learning and the achievement of leadership competencies. According to Kolb (1984) learning is the process of knowledge created through the transformation of experience. Kolb stated that "knowledge results from the combination of grasping experience and transforming it” (p. 41). Traditional classroom learning 
techniques may have ignored the learning process that takes place between students in a work experience, particularly those students who are new to an industry.

Much of the skill essential for effective leadership is learned from experience rather than formal training programs. Special assignments can provide an opportunity to develop and refine skills while performing regular job duties (Yukl, p. 467). Eyler (2009) suggests that (a) experiential learning can "boost" an individual's capacity for critical thinking and application of knowledge in complex and ambiguous situations, which are critical leadership traits, and (b) it improves the individuals' ability to engage in lifelong learning, including learning in the workplace (p. 26). The experiential learning experience can provide an opportunity for students to enhance their formal training while learning skills that are important to effective leadership.

The importance of the various skills achieved depends upon the environment and how learning takes place. Leadership behavior can be "contextually-based" and the skills and abilities required by an individual can depend on various factors (Brownell, 2007). The nature of the hospitality environment may be a factor that impacts how learning takes place and thus how competencies are achieved. Tesone (2004) posits a learning model called "whole brain leadership development for hospitality managers", with application of knowledge, experience and reflection, as a way to enhance leadership abilities (p. 363). It will be valuable to understand the perceptions of the interns regarding the competencies that they gained during experiential learning as well as supervisors' perception of the leadership competencies gained by the intern. This study will serve to further understand the relationship between experiential learning and gaining essential hospitality management leadership competencies. 


\section{Research Questions}

An objective of a research question is to "operationalize" the proposed research (Mertens, 2005, p. 344). This study will be used to gain a greater understanding of the competencies that interns gain during experiential learning and their perception of the competencies gained. In order to deliver high-quality, industry-relevant education, hospitality management educators must continually identify and investigate current and evolving competencies for future managers and leaders (Kay \& Russette, 2000). This study will address the following questions:

1. How do interns perceive their growth as a leader during their hospitality management internship experience?

2. What are the interns' perceptions of their communication skills?

3. What are the interns' perceptions of their interpersonal skills?

4. What are the interns' perceptions of their financial management skills?

5. What are the interns' perceptions of their technology skills?

6. What are the interns' perceptions of their marketing skills?

7. What are the supervisor's perceptions of the leadership competencies and knowledge gained by interns during the internship experience?

Addressing those questions will provide a framework for exploring experiential learning in the workplace and the information gathered will be used to gain a greater understanding of the competencies interns gained during their experience. 


\section{Social Construct of Learning}

Learning takes place in collaboration with others through an authentic learning context from the traditional constructivist view of education. The experience of collaboration can "help move students toward incorporating into their intellectual work much of what they learned about working interdependently in their many experiences outside the classroom" (Bruffee, 1999. p. 20). Collaborative learning tasks do not ask “yes or no?” but may ask "why yes or why no"? Instead, collaborative learning tasks are constructive tasks that draw students into a constructive process. The result is a "nonfoundational" social construct that students arrive at by self-discovery (Bruffee, p. 30). Gill (2010) states that "collaborative learning is the second level of organizational learning, leveraging collective knowledge and wisdom from a group of people" (p. 75). Principles of constructivist education include: designing the task and learning environment to reflect the complexity of the environment where students are able to function at the end of the learning providing opportunity and support for reflection on both the learning context and the process (Savery \& Duff, 1996, in Zwaal \& Otting, 2007, p. 256). The shift towards a constructivist conception of education has changed the concept of how knowledge is gained by students in the workplace. There is a shift in focus from learning "facts" towards learning "competencies". Competencies are defined as "knowledge, skills and affections" (Zwaal \& Otting, p. 257). With learning in context, new learning concepts have emerged, such as learning to learn, problem solving and leadership development. From the constructivist view, the students should view their learning as a social process, as well as a process of enculturation in a community of practitioners (Zwaal \& Otting, p. 258). 
The social construct for an individual new to a company is often realized at the organizational level during the orientation and training process. Organizational socialization is a process of adaptation, or "learning the ropes" through becoming an insider. It has been defined as "the process by which newcomers come to understand and appreciate the values, abilities, expected behavior, and social knowledge essential for assuming an organizational goal and for participating as an organizational member" (Young \& Lundberg, 1996, p. 26). Formal processes, such as orientation and training, and informal processes, such as conversations and observations, help the newcomer learn what the organization is about and what will be expected of them.

Orientation and training are forms of the formal organizational socialization process. Organizations increasingly use training as a socialization process, which can be used to influence newcomers' behavior and attitude towards the organization (Young \& Lundberg, p. 28). Training and orientation processes may not be enough, however, to benefit the newcomer to the socialization process. The relationships and interactions, both formal and informal, may be of great benefit to helping the new person adjust and assimilate into the social process that exists in organizations.

Lave and Wagner's “Situated Learning” (1991) concept provides further discussion into the value of learning and the social process. Newcomers to a community becomes members through "legitimate peripheral participation", where mastering skills and knowledge and participating in the practices related to the "community", in this case the hospitality industry, provides for full membership in the "community".

The term "informal learning" has been used in adult education for some time now. It provides a contrast to formal learning and has increasingly been used in adult 
education for several reasons (Eraut, 2004, p. 247). First, informal learning implies greater flexibility for the learner which is in contrast to many formal learning environments. Second, the informal learning process considers the socialization involved in learning from others in the activities and events that take place in a wide variety of settings. Third, informal knowledge is also knowledge gained through experience, both personal and structured work experience (Eraut, p. 248).

Eraut (2004) suggests that "implicit learning" is a characteristic of informal knowledge. Reber (1993) expands Eraut's definition as “the acquisition of knowledge independently of conscious attempts to learn and in the absences of explicit knowledge about what was learned" (Eraut, p. 250). Eraut argues that most learning from experience has some implicit learning aspects, and that awareness of explicit learning does not mean that implicit learning is not also taking place. He identifies two additional types of informal learning. One is reactive learning, which is reflective learning - noting facts, asking questions, observing effects of action and recognizing future learning opportunities. The second is deliberative learning, where there is definitive learning goals and engagement in decision making, problem solving and rehearsing for future events (Eraut, p. 250).

Peter Drucker (1968) stated that “today, the center [of our society's productivity] is the knowledge worker, the man or women who applies to productive work ideas, concepts, and information" (p. 264). Nonaka (1991) identifies two similar types of knowledge that individuals gain through creating new knowledge and becoming "knowledge workers" (p. 97). First is explicit knowledge, which is formal or systematic knowledge, and can be product specific. This can be similar to skills or abilities. Second 
is tacit knowledge, which is part technical knowledge with an important cognitive dimension. Tacit knowledge is highly personal and is gained though an individual's perspective, insights, and knowledge, both informal and formal, gained through the experience (p. 99). Personal knowledge can be transformed into organizational knowledge, which has the potential to "spiral" through the entire organization. When an individual's personal knowledge becomes available for others, the activity of knowledgecreation can thrive.

The final key to knowledge creation is the process of creating an actual model. In the model, "contradictions get resolved and concepts become transferable through consistent and systematic logic" (Nonaka, p. 101). The internship is a key component of the hospitality management students learning experience, which is the process of "modeling" the knowledge and concepts that they have gained through coursework. Experiential learning, particularly in the form of an internship, is an important link that allows the intern to crystallize the knowledge that has been gained, and to converting tacit knowledge to explicit knowledge.

\section{Individual Learning}

Individual learning can be examined from two perspectives - cultural or social knowledge and personal or individual knowledge. The social perspective draws attention to the social construct of knowledge and the wide range of practices and activities that use learning. The personal perspective of learning focuses on the individual's exploration of thinking, interacting, performing, and interpreting what was learned (Eraut, p. 263). 
Individual learning can be considered the first level of learning and the basis for the collective learning that takes place in teams and organizations. According to Gill (2010), "learning at an individual level in organizations occurs when a person acquires new knowledge, skills, attitudes and beliefs that change the way the person perceives the world, understands information, and performs on the job" (Gill, p. 53). When it comes to learning an applied practice in a formal organizational setting, the two reception points for the individual's learning system seem to be knowledge and experience (Tesone, $\mathrm{p}$. $364)$.

Moore (2007) defines knowledge as the "capacity to act effectively in the world in respect to some situated goal, to recognize, to understand, to make sense and to do" (p. 183). Knowledge can take various forms such as facts, explanations and skills. However," knowledge-in-use", or working knowledge, is knowledge and learning, which is what an individual knows through work experience. Knowledge can be seen as a process or activity, not a product, and thus the activity can impact or change the knowledge gained. As individual's process new knowledge, transformation can take place, both on a personal level and within the individuals work context.

Learning combines four basic elements: the experiences we have, the opportunity to practice and embed those experiences in our long term memory, the conversations and interaction we have with others, and reflection; we learn through what we do, through what we see, and what we hear (Jennings \& Wargnier, 2010, p. 14).

Through individual learning, three kinds of abilities can be developed: technical skills, relationship skills, and learning-how-to-learn. Methods for individual learning should fit the learning objectives and be tailored to the learner. There are several tools 
that can be used by the individual learner to create and achieve personal as well as organizational learning goals. The tools include personalized learning plans, selfreflection, journals, job rotation, coaching and mentoring, and on-the-job training (Gill, 2010). Several significant factors can also affect the learning effort. The challenge and value of the work involved, the confidence and commitment of the individual, and the feedback and support received from colleagues and superiors can all impact the quality of the retention of knowledge (Eraut, p. 269).

Structured on-the-job (OTJ) training is a form of individual learning and it is the planned process of developing task-level expertise by having experienced staff train novice staff at or near the actual work setting (Jacobs \& Jones, 1995). The steps in the process of OTJ differs among industries and organizations, but most follow similar steps of preparing the learner, presenting training, receiving a response from the learner, and performance feedback and evaluation from the trainer. According to Gill (2010) if an organization neglects the OTJ process, it will be "missing a prime opportunity to facilitate staff learning and will be leaving to serendipity the development of knowledge, skills and attitudes, and that it's the people who will help the organization reach its potential” (p. 71).

Eraut (2004) suggests that acquiring professional, managerial and technical knowledge is complex and involves the simultaneous use of different types of knowledge and skills, which have to be learned holistically. Even though a performance can be broken down into successive phases, each phase requires several different types of knowledge and skills, the importance varying from one situation to the next (p. 257). Learning through a work experience, both formal and informal, can provide individuals 
with work-integrated learning. Many organizations now see the value of better understanding the new-employee socialization process and the role that individual learning plays in gaining valuable knowledge and skills.

\section{Experiential Learning}

"Experiential learning exists when a personally responsible participant cognitively, affectively, and behaviorally process knowledge, skills and/or attitudes in a learning situation characterized by a high level of active involvement" (Hoover \& Whitehead, 1975, p. 25). Experiential learning is "participative" and the student must be involved in the process. Experiential learning is active rather than passive (Gentry, 1990, p.13). The experiential learning process draws upon the concept of experiential education, which is the teacher to student process, and in the case of this study employer to intern, that infuses direct experience in the learning process.

Experiential learning programs can be traced back to 1906 when Herman Schneider, Dean of Engineering at the University of Cincinnati, started an experiential learning program, called cooperative education, to provide work-based experience to engineering students (Ryder, 1987, in Lee \& Dickson, 2010). The interest in adding an experiential learning component to academic curricula gathered supporters after the University of Wisconsin-Stout received the Malcolm Baldridge National Quality Award, contributing their success to the fact that every student that graduated participated in experiential learning (Furst-Bowe \& Wentz, 2006).

The concept of work education (Simon, Dippo, and Schenke, 1991) is closely related to the policies that link schools to the economy. The teaching curriculum has 
often been tied to the business economy, and in this case, the hospitality industry seeks students with business industry competencies from work-integrated education. Koppel (1976) emphasized the importance of a closer reliance between academia and industry, such as implementing field experience in hospitality management programs. In maintaining a competitive edge, organizations will need to identify the competencies, knowledge, and skills required to thrive and grow. In Simon, Dippo \& Schenke, the market value of knowledge is explored and what specific knowledge is more valued.

Learning is also the process of knowledge created through the transformation of experience. According to Kolb (1984, p. 41), "knowledge results from the combination of grasping experience and transforming it”. Kolb's Experiential Learning Model proposes that experiential learning has six main characteristics. The characteristics include learning as a continuous process grounded in experience, learning as a holistic process of adaptation to the world, learning as a process of creating knowledge that is the result of the transaction between social knowledge, and personal knowledge (Kolb, 184, p. 41). Kolb identified concrete experience - learning from specific experiences and relating to people - as an important component on the experiential learning continuum. Taking outside experiences and integrating them into the classroom creates a dynamic known as seamless learning (Kuh, 1994, 1996). This involves incorporating the student's non-classroom experiences with the academic environment. Seamless learning provides a student with a more complete learning experience.

Jennings and Wargnier (2010) identified research that considers the value of experiential learning. The approach is based on research that produced the 70:20:10 model, which demonstrates that 70 percent of learning stems from experience. A total of 
20 percent is acquired through others and only 10 percent is the result of structured courses and programs. Therefore, experiential learning represents 90 percent of overall learning (p. 16).

Experiential learning is one of the most important aspects of the hospitality program's curriculum $(\mathrm{Fu}, 1999)$. Hospitality management students consider experiential learning to be the most effective way to learn the reality of the positions they are considering for their future career (Scott, 1992). These objectives can be achieved by the student in an experiential learning situation through several methods. One method is hands-on familiarization with a professional environment, which encompasses the work requirements, enabling one to relate and adjust their academic experience to the demands of the practice (Tobias, 1996, p. 142).

For many hospitality management students, acquiring a satisfying career is the main purpose for pursuing a college degree (Mau \& Fernandes, 2001). Hospitality educators are aware of this, thus the goal of hospitality education is to produce individuals who can think, lead, and solve problems (p. 581). Wilson (1970) concluded that "the nature of cooperative education is with education in which the learning experiences have been carefully planned in the light of educational objectives to be achieved" (p. 4). Canjar (1987) claimed that it was obvious that cooperative education enhances the academic program. Morgan (2004) suggests that regardless of the level of knowledge gained by the student in their experiential learning environment, the placement will impact their classroom experience. If education is a process of changing behavior through experience, then experiential learning opportunities in hospitality management programs are a component of the process that help students acquire the 
skills for a satisfying career. Raymond and McNabb (1993) found that internships and projects provide a real-world experience and combined with academic skills learned in the classroom, help to provide students, upon graduation, with a competitive advantage in the workplace (p. 2).

\section{Internships as Experiential Learning}

Learning can take many forms, and an internship is one form of active learning (Solnet, Kralj, Kay \& DeVeau, 2009). Though there is no perfect internship model, an internship should be highly structured and provide a format that provides a framework for achieving the goals. The goals of an internship should address the needs of the primary stakeholders and attempt to advance the benefit of the internship practice for all involved (Zopiatis \& Constanti, 2012, p. 44). Students and employers are increasingly demanding more effective ways to accelerate professional readiness and reduce uncertainty in the hiring process. An effective internship program can help students and employers ensure an opportunity to maximize their return (Tobias, p. 4). There are a number of studies that have explored the value of the internship experience to students. Five main categories have emerged that frame how students value the experience: the actual learning experience, academic benefits, financial benefits, career benefits and the benefit of selfactualization (Zopiatis \& Constanti, p. 44).

According to the National Association of Colleges and Employers (NACE) 2010 Employer Internship Survey, 83.4\% of employers surveyed said that internship programs help the organization recruit entry-level college graduates (National Association of Colleges and Employers, (2010, April). Internship Programs Feed Full- 
Time Hiring, retrieved August 14, 2011 from http:// www.naceweb.org). The survey also found a correlation between participating in an internship and staying on the job. Similarly, the NACE 2010 Student Survey found that new graduates who participated in an internship were more likely to receive a job offer than peers who did not participate in an internship.

In a survey of the membership of the Council of Logistic Management (Knemeyer \& Murphy, 2001) just over $90 \%$ of the respondents agreed that an internship should enhance the placement of the student and $84.9 \%$ reported that internships should aid organizations in recruiting full time. In a survey of Fortune 500 recruiters, Barr and McNeilly (2002) discovered that approximately $40 \%$ of the recruiters reported that certain factors that are part of the internship, including leadership experience and teamwork, cannot be taught in the classroom...the traits are learned from participation in activities and work-related experience (Cook, Parker, and Pettijohn, 2004, p. 180). Cannon and Arnold (1998) found that students are using internship programs as a way to gain a competitive edge in the recruiting process.

Most hospitality management programs have emphasized the importance of experiential learning through internship opportunities (Lam \& Ching, 2006). This type of work-integrated learning provides participants with the ability to develop specific competencies, attitudes, and transferable skills. Similarly, active learners, who gravitate to active experimentation, learn materials through "taking information and doing something with it in real life - discussing, explaining and testing it” (Lee \& Kamp, 2005, p. 28). The cornerstone of developing a pedagogically sound and effective internship is that it is based on a triangular commitment of all the stakeholders involved; the student, 
the hospitality organization and the educational institution (Zopiatis \& Constanti, p. 50). Through studies and experience, students, industry professionals, and academic faculty, have found to benefit from the internship experience.

From the student's perspective, an internship provides a valuable learning experience and enhanced employment opportunities (Cook, Parker \& Pettijohn, 2004, p. 181). The internship provides students the opportunity to work with industry professionals and observe first-hand the processes involved in their future job. There is increasing awareness among graduates that an internship may enhance their ability to obtain the job they want in the industry. Gault, Redington and Schlager (2000) concluded that: business students who participated in internships were able to find employment more quickly than those who did not participate; internships resulted in higher starting salaries and job satisfaction, while providing business with more qualified prospects and improved relations with the sponsoring university.

Internships also appear to help students relate their classroom experience to the work experience. Ju (1997) notes that internship programs provide students with the opportunity to test their career choices while they are still in college. A well structured internship can provide a positive experience for the participant and enhance the likelihood that the student will strongly consider the career path. The hospitality curriculum should provide a connection to the internship practice to minimize the gap between hospitality education and the hospitality industry practice (Zopiatis \& Constanti, p. 49).

The industry also benefits from the internship experience. The employer that participated in the internship typically discovers that internships provide a good source of 
current information, knowledge workers, and exposure to the skills of potential employees (Cook, Parker \& Pettijohn, p. 181). Raymond and McNabb (1993) found that the most effective method for helping students obtain the skills that business considers the most important were internships, along with other projects, cases and simulations. Internships also benefit the participating organizations by providing recruitment leverage and value from the student participant's work. One long-term benefit of the internship to the industry employer is the opportunity to be seen as a socially responsible employer. Social responsibility enhances the industry, and participating organization's, commitment and contribution to the community (Thiel \& Hartley, 1997). There is also the opportunity for knowledge transfer, whereby the student, upon returning to the academic environment after completion of the experiential learning experience, may better apply their new knowledge to enhance learning efficiency (Tobias, p. 158).

Although internships have been effective for students, employers and educational institutions, internship programs have their challenges. Hite and Bellizzi (1986) suggest that if internships are not carefully thought out, it could result in a disappointing experience for the student (p. 181). Three areas that can account for a disappointing experience are unclear standards, misunderstanding by the student regarding the merits of the job, and misrepresentation of the organization regarding the duties required by the intern (Hite \& Bellini, p. 182).

The best learning is first person, present tense, experiential (Crosbie, 2005, p. 50). An internship is a mechanism for real-life application of the skills that are important to the hospitality industry in particular. Experiential learning, or internships, can engage students at the emotional and cognitive levels that form deeper, longer lasting learning 
(Hawley, 2005; Kolb, 1984). Perry (1989) found that business professionals in particular think internship are a key part of the academic experience because they make students think (p.1). Some of the objectives that should be accomplished by the participants during the internship include the development of conceptual knowledge, management skills, communication skills, and career development skills (Barrows \& Bosselman, 1999). The experience gained from internships can enhance students' ability to be a team-player, innovator and risk taker (Raymond \& McNabb, p. 4) as well as gain the personal and interpersonal skills associated with leadership (Crosbie, p. 50). Learning skills through the internship experience are a valuable addition to the formal training achieved in the experiential learning process.

\section{Internships and Leadership Development}

Leadership development is a multibillion dollar business in the United States (Fulmer \& Vicere, 1996). Running leadership development programs can be expensive, but many CEOs and corporate leaders find them valuable. According to Geoff Colvin, "companies that were not serious about leadership development are getting serious. Of the many powerful forces driving companies to develop leaders more effectively, the most important is the world economy's long-term shift from dependence on financial capital toward human capital" (Fortune Magazine (2007, September 20). How Top Companies Breed Stars, retrieved June 30, 2012 from http:// www. cnnmoney.com). One of the biggest investments by companies in developing future leaders is not only hard dollars, but time. The executives and senior managers of organizations are investing time in developing individuals and leading by example, coaching and mentoring. One of the 
biggest changes at most companies is the practice of identifying leaders early. According to General Electric Company's John Rice, "we begin to evaluate leadership capability on the first day of employment. Many employees have interned at GE for at least one summer, enabling the company to observe the way interns get others to work with them when they have absolutely no authority".

Over the years the hospitality industry has realized an increased need for a "leadership style" in managers versus a "control style", with an emphasis on strategic and corporate skills instead of operational and technical skills (Umbriet, 1993; Raybould \& Wilkins, 2006). To understand leadership style, they must first explore how a leader is developed. So how do they learn the skills and competencies of an effective leadership? Conventional wisdom sees leadership as a good thing that we need more of, at least the right kind. Yet there is confusion and disagreement about what leadership means and how much difference it can make (Bolman \& Deal, 2008, p.342).

Nasr (2004) suggested that leadership skills are gained through experiential learning and that it benefits students in a tangible manner. Experiential learning "has the potential to produce a student with a higher aptitude for obtaining the soft skills, or leadership skills, employers in today's market so desperately seek" (Lee, 2008, p. 13). Soft skills training commands a large percentage of the dollars spent on training in organizations and is the focus of most leadership development (Crosbie, 2005, p. 45). Tas (1988) argued for the inclusion of a structured internship within degree programs to provide real world experiences and gain soft skills such as communication skills, managing human relations, creating a positive work environment, and initiative. Tas conducted a survey to identify the most important competencies for hotel general 
manager trainees. From the 75 respondents to the survey, 36 competencies deemed essential to important for hospitality managers were identified and ranked. Tas suggested that the hospitality internship has the potential to satisfy most of the competencies a management trainee should acquire and a structured internship would greatly facilitate the process of developing primary competencies (p. 43). There is research that has identified other areas that should be included in the internship experience: leadership and skills training, services marketing, total quality management, financial analysis, and communication skills (Getty et al., 1991; Umbriet, 1992).

Tesone (2004) posits a whole-brain leadership model to describe the learning process that may be applied to the development of leadership skills (p. 363). Tesone connects leadership and learning theory and designs a model for hospitality management trainees to develop the skills identified by Crosbie and in support of the value of the internship in gaining those skills, as discussed by Tas. The model identifies knowledge and experience as the two reception points for an individuals learning system. Knowledge is defined as information that is cognitively gained by the individual and experience is the individual's visceral representation of an event or related events (Tesone, p. 364). The model provides an "experiential learning loop" which creates interdependency between knowledge, experience and reflection. The process is intended for the individual to enhance leadership abilities through the fusion of knowledge gained through learning process and experience gained through hands-on training. Knowledge and experience, combined with contemplation of the processes used to gain leadership skills, completes the experiential learning loop (Tesone, p. 367). Having experience allows for faster training time for an individual, and enhances a person's ability to 
respond "intuitively" to a situation, which is a benefit of the experiential learning loop. Arendt and Gregoire (2008) completed a study on hospitality management students that suggests a positive relationship exist between leadership skills and practices, and students who reflect on self-behavior and actions. The ability to reflect on ones actions, and change action based on reflection, may be a valuable leadership development tool.

Lee (2008) also suggests that students who participated in experiential learning gained valuable leadership skills that improved financial management skills, ability to view career expectations more realistically, increased ability to take initiative, improved leadership skills, increased ability to adapt to change, and greater knowledge of the hospitality industry.

Leadership competencies can be developed in a variety of ways and in varied environments. Formal training, development activities, and self-help activities are approaches to leadership competency development (Yukl, p 459). Formal training and development activities are frequently used in organizations for leadership development. Formal leadership training programs can take several forms, ranging from one-day workshops to a year or more of a broad range of skills, and are often designed on a particular leadership theory, like situational leadership theory (Yukl, p. 460). In addition to designing training based on a leadership theory, specific methods that are ideal for individual leadership competency development are available.

Learning from experience is a valuable method being used by organizations large and small. Much of the skill essential for effective leadership is learned from experience rather than formal training programs (Davies \& Easterby-Smith, 1984; Kelleher, Firestone, \& Lowy, 1986; Lindsey, Homes, \& McCall, 1987; McCall, Lombardo \& 
Morrison, 1988). The type of experience that an individual is afforded can greatly impact the effectiveness of the leadership development. Leadership competencies gained through experience can be affected by several factors. One is the amount and difficulty of the challenges the individual encounters during the experience. Second is the diversity and variety of the tasks involved, and third is the level of accurate feedback that is received by the individual during the learning experience (Yukl, 2010).

There are additional factors that can affect the leadership development process. Feedback from colleagues and senior leaders, assimilation and inclusion into the workgroup, expectations of performance, and creating an environment that supports informal learning, are all factors that can affect the experiential learning process for individuals.

\section{Leadership Competency Models}

A model is simply a presentation of the real world. Models help us simplify complexity and are tools for making things visible (Gill, p. 173). Eraut (2004) states that "competence in North America and in management is an individual-centered definition and refers to a personal attribute or quality, while elsewhere is has a social-centered definition and refers to meeting social expectations" (p. 264).

A competency model is a "descriptive tool that identifies the knowledge, skills, abilities and behavior needed to perform effectively in an organization" (Chung-Herrera, Enz \& Lankau, p. 17). The focus of competency models is behavior of the individual rather than personality, which may be more difficult to measure. Competency models have historically been used by human resource departments to establish criteria for a 
wide range of personnel systems. Competency models are used by organizations to help identify the behavior needed to perform effectively and successfully and are a common language for discussing capabilities and performance. Identifying the relevant competencies for industry professionals can assists with developing future leaders. The process also helps combat the challenges in the recruitment and selection, training and career development, and change management in an organization (Chung-Herrera, et al, p. 17).

\section{Hospitality Education and Leadership Competencies}

To better facilitate the process of identifying important leadership skills, hospitality industry managers and leaders have begun to use competency models as a tool to identify the crucial knowledge, skills, and abilities (KSAs) that hospitality leaders will need for success. Early research on the KSA's important for lodging managers suggests that leadership and interpersonal skills were the competencies most recognized by hospitality professionals (Kay \& Moncarz, 2004). The consensus among hospitality professionals over the years has been that human-resource related skills were believed to be the most important skill. Kay and Moncarz identified four KSA domains that ranked most important for hospitality management success, and each domain had specific skills and abilities that are part of the management and leadership development.

The domain of human resources management includes the following areas for development: Being a leader, motivating employees, developing positive human relations, building teams, having knowledge in quality assurance, and managing employee grievances. The domain of information technology includes the following areas for development: using email, using internet resources and research, having knowledge 
about property management systems, reservation systems, and operational application software. The domain of financial management's areas for development include controlling costs, planning and budgeting, knowledge in operational analyses and managing cash flow. The last domain, marketing, include areas for development such as following organizational vision and mission, making deals, achieving measurable results, and using sales techniques.

A leadership-based competency model specific to the lodging industry was developed to provide the industry with a functional competency model. The model was designed for organizations to use for leadership development, understanding individual competencies for career advancement, for hospitality management curriculum design, and for students to craft career paths (Chung-Herrera, et al, p. 18).

A future-oriented competency model was developed with the lodging industry in mind. The model is a behavioral-based competency model that identifies the most important dimensions of a leader's behavior. The competencies were identified through hospitality leader's feedback. The feedback resulted in the identification of eight "overarching" competencies - communication, critical thinking, implementation, industry knowledge, interpersonal skills, leadership, self-management, and strategic positioning - that are desired by the lodging industry. Leadership, specifically, had six specific competencies that aligned with leadership competencies desired across various industries. The six leadership competencies are: developing others, embracing change, fortitude, fostering motivation, leadership versatility, and teamwork orientation (ChungHerrera, et al., p. 21). Sandwith (1993) presented research on the competency domains of general management, which extended on the work of Katz (1955) who had identified 
three fundamental skills essential for any manager: technical, human and conceptual. Tas (1998) identified six essential skills that were primarily related to human resource skills. Competencies for entry-level food and beverage workers that are essential for all stakeholder groups were found to be human resources, leadership and communication (Okeiyi et al, 1994). Diverging opinions have emerged over what core competencies are essential to the success of the hospitality professional. However, Sandwith suggested that changes in the business environment over the years shifted to a need for broad skills associated with leadership such as interpersonal, financial, and technical, from simply controlling and directing.

A study to determine the essential competencies needed by successful lodging managers was published by Kay and Russette in 2000 . The population for the study was a group of managers from multiple functional areas with a broad span of control. The study concluded that the essential competencies required for success by hospitality managers fall into five skill categories. The five categories are leadership: interpersonal, conceptual, creative, administrative, and technical. The respondents to the study ranked the competencies that fell under the leadership domain as representing the skills designated as essential competencies (EC), with interpersonal and technical skills ranking second and third respectively, and conceptual-creative and administrative skills fourth and fifth (Kay \& Russette, 2000, p. 61). The study conducted by Kay and Russette in 2000 supports several of the early studies regarding the essential competencies needed for managers and leaders.

Identifying the core leadership competencies that should be achieved by interns is a continuous task of industry leaders and academic professionals. Educational institutions 
and hospitality organizations that provide internships have a responsibility to ensure that internships provide students with the experience that will enhance their professional knowledge, skills and abilities (Zopiatis, 2007).

\section{Stakeholder Perception}

The move to a "learning orientation" from a "teaching orientation" has been a significant shift in the approach to education (Chonko, 1993). The move involves attention to learning styles and to experiential learning methods to improve learning outcomes (Duke and Reese, 1995; Roach, Johnston and Hair, 1993). One approach to evaluating and measuring individual learning outcomes is to identify stakeholder perception. Perceptions of the achievement of learning outcomes may suggest how well the learning program is developing the student (Duke, et. al). Using student perception is one critical stakeholder evaluation. Student perspectives may be less developed by their limited exposure to the work environment, but their perceptions are important to the process of assessing learning outcomes and to building their confidence in skill development (Duke, 2002, p. 215). A recent case study that examined the perception of interns' attitudes towards an internship program found that interns in the study were in agreement that the experience had given them more confidence in finding a job upon graduation (Cook, et. al, p. 182).

Jeonguen Ju (1997) studied perceptions and overall satisfaction levels of the effectiveness of hospitality management internships. The study showed that previous work experience was the most common factor influencing students' perception of their internship experience. Nelson (1994) conducted a study that revealed that students were 
most satisfied with internships that provided relevant work, some autonomy, and time feedback.

Industry leader's perception of the experiential learning process is also a vital component in designing the internship experience and evaluating the learning outcomes and skills achieved by the intern. Barr and McNeilly (2002), in a study of Fortune 500 recruiters, found that approximately $40 \%$ of respondents found that certain components of the internship, including leadership exercises and team work, cannot be taught in the classroom. A commitment to a genuine and relevant learning experience by internship providers is a key component to a successful outcome for all stakeholders.

There is controversy and divergent perspectives on the definition of good leadership. Studies have cited a long list of attributes associated with effective leadership: risk taking, flexibility, self- confidence, intelligence, interpersonal skills, courage, task competence, decisiveness, honesty, to name a few (Bolman \& Deal, p. 346). The oldest reliable finding about effective leaders - they are smarter and work harder than other people - continues to find research support (O'Reilly and Chatman, 1994). Regardless of the divergent opinions, experiential learning as a leadership development tool has emerged as being valuable to the learning process for students. The hospitality management internship is an important component of the overall learning process in gaining the knowledge, skills and abilities attributed to successful leadership. The perspective of the industry stakeholders, particularly interns and internship supervisors, will assist in gaining more knowledge regarding the relationship between experiential learning and the achievement of leadership competencies. A well structured 
internship can maximize the potential to achieve the competencies most desired by the hospitality industry to maintain a competitive edge.

\section{Summary}

The literature reviewed for this study provides a conceptual framework for understanding the perception of stakeholders in an experiential learning environment and leadership competencies achieved. Previous research on hospitality management program internships has focused on the process and design of internship programs, and not perceptions and specific competency levels of students upon completion of the internship. The research questions are designed to provide an in-depth exploration with individuals regarding perceptual information and leadership learning in an internship experience. An individual's personal experiences can influence many of their decisions. The literature in this review assists in guiding the research to answer the questions of how perception and experience may influence and direct the intern's leadership development. The hospitality industry is a changing industry and maintaining success through change requires the knowledge and experience to compete. The literature suggests that gaining the required knowledge and skills of the future are enhanced by experiential learning. The data collection and analysis process for this study will provide information on the achievement level of several competencies by interns through experiential learning. This study will contribute to the research that is still evolving on the relationship between experiential learning and gaining the skills and knowledge valued by future leaders in the hospitality industry. 


\section{Chapter III}

\section{Research Methodology}

Hospitality industry organizations are faced with the task of developing future leaders who will have the skills necessary to adapt to the forces creating change in the industry. Hospitality industry leaders have begun to identify the competencies, or crucial knowledge, skills, and abilities required to forge organizational goals, particularly in a global economy. One of the tools used to meet the challenge of developing leadership competencies starts with students in experiential learning or internships, which are integrated into the academic curricula. Hospitality management students who participated in an experiential program, as compared to those who did not, had a better understanding of how hospitality organization's function, had an increased ability to adapt to change, as well as demonstrated improved leadership and financial management skills (Lee, 2007).

Over time, three fundamental skills essential for any manager were introduced; technical, human, and conceptual (Katz, 1974). Technical skill involves an understanding of, and proficiency in, a specific kind of activity, a skill that requires specialized knowledge. Human, or interpersonal skill, requires effective communication and involves working with people and understanding their behavior. Conceptual skill is the ability to view an organization as a whole as well as the ability to understand the organization within its environment (Gregoire, 2010, p. 278). However, changes in the business environment over the years shifted to a need for additional skills associated with leadership such as financial management, information technology and marketing skills. 
The implication is that the knowledge, skills, and abilities needed by managers and leaders have changed through the years (Kay \& Moncarz, p. 286). This may also suggest that there is not a consensus on one set of core competencies that the industry has agreed upon, but that the ideal variety of skills may depend upon the variables in the individual's environment. Integral to developing leadership competencies is the ability to understand how interns learn, and particularly how they shape learning in an experiential learning environment.

This study will seek to understand how interns perceive their leadership competencies prior to and upon completion of their hospitality management internship. The study will also seek to understand the perceptions of the supervisors at the internship location. An important component of the research is the supervisor's perception and evaluation of the intern's leadership competencies and skills upon completion of the internship. Much of the skill essential for effective leadership is learned from experience rather than formal training programs. Special assignments can provide an opportunity to develop and refine skills while performing regular job duties (Yukl, 2006). The importance of the various skills achieved depends upon the environment and how learning takes place. Leadership behavior can be "contextually-based" and the skills and abilities required by an individual can depend on various factors (Brownell, 2007). The nature of the hospitality environment may be a factor that impacts how learning takes place and thus how competencies are achieved. Tesone (2004) proposes a learning model called "whole brain leadership development for hospitality managers", with application of knowledge, experience and reflection, as a way to enhance leadership abilities (p. $363)$. 
It will be valuable to understand the perceptions of the interns regarding the competencies that they gained during their experiential learning experience as well as supervisor's perception. Previous research on hospitality management program internships has focused on the process and design of internship programs, and not perceptions and specific competency levels of students upon completion of the internship. Their perceptions are relevant to understanding if the objective of each participant was achieved and to what extent were competencies gained. This study will serve to further understand the relationship between experiential learning and gaining essential hospitality management leadership competencies. This research will provide valuable information regarding the social phenomena that is part of leadership development, as well an in-depth understanding of the competencies achieved through experiential learning.

\section{Research Questions}

An objective of a research question is to "operationalize" the proposed research (Mertens, 2005, p. 344). This study will be used to gain a greater understanding of the competencies that interns gain during their experiential learning experience and their perception of the competencies gained. In order to deliver high-quality, industry-relevant education, hospitality management educators must continually identify and investigate current and evolving competencies for future managers and leaders (Kay \& Russette, 2000). This study will address the following questions:

1. How do interns perceive their growth as a leader during their hospitality management internship experience? 
2. What are the interns' perceptions of their communication skills?

3. What are the interns' perceptions of their interpersonal skills?

4. What are the interns' perceptions of their financial management skills?

5. What are the interns' perceptions of their technology skills?

6. What are the interns' perceptions of their marketing skills?

7. What are the supervisor's perceptions of the leadership competencies and knowledge gained by interns during the internship experience?

Addressing these questions will provide a framework for exploring experiential learning in the workplace and the information gathered will be used to gain a greater understanding of the competencies interns gained during their experience.

\section{Description of the Population}

The population for this research will include interns enrolled in a 4-12-credit Internship in the Hospitality Management Program in the Department of Human Environmental Studies at Southeast Missouri State University and the supervisor of each participating intern. The study will include 6 undergraduate students completing the internship requirement for the Bachelor of Science Degree in Hospitality Management. The internship is a career-related work experience in Hospitality Management. The internship focuses on management skill development in an environment that allows application of knowledge and concepts previously acquired in the classroom. The internship should provide first hand exposure and practical considerations involved in performing managerial tasks at the internship site. The tasks may relate to organizational structures, decision-making processes, quantitative skills and implementation procedures 
(Southeast Missouri State Hospitality Management Program Internship Requirements, 2012).

The internship requirements for enrolling in the internship are: completion of 75-credit hours; 9 hospitality management specific courses; and a grade point average (GPA) of 2.5, both cumulative and in the hospitality management major.

The hospitality management specific courses are designed to introduce the student to the theory and concepts of hospitality management and add experiential learning in the form of culinary education, event and meeting management, lodging operations, management, and marketing courses. These courses allow the students to gain knowledge about the industry that helps prepare them for experiential learning. The specific courses that are required by hospitality management students include: introduction to hospitality management, selection and preparation of food, hospitality law, food, beverage and labor cost control, hospitality law, culinary theory and practice, hospitality sales and marketing, hospitality and institutional management, quantity food production, and event/meeting administration.

Completion of the internship is a graduation requirement of the hospitality management bachelor of science; however, the use of the participant's information for research purposes is strictly voluntary. The participants all have to meet the same academic requirements for enrolling in the internship, and there are no incentives, compensation, or extra credit offered to the students for participation.

The population for the research will also include the supervisors assigned to each intern at the internship location. The supervisors assigned to each intern will be experienced in that area and may provide direction on technical, interpersonal and 
conceptual skills. The supervisor at each internship site will provide direction to the intern on the duties and tasks assigned to achieve the organization's objectives. The supervisor will also provide an evaluation based on their perception of the competencies the intern achieved during the internship.

The internship sites participating in the experiential learning program are varied. The interns have the opportunity to join an organization that allows them to gain the knowledge and experience in the area specific to their career goals. The hospitality industry spans several sectors: lodging, foodservice, travel, tourism, meeting and event management, entertainment, and attractions. The students can thus identify areas that are of most interest to them. Though the internship advisor assists each intern with placement in their chosen organization, it is primarily up to the student to locate and secure their internship site.

Key to the success of the internship is to make sure that all of the stakeholders involved - the interns and the internship organization - are committed to the learning experience. The commitment by all of the participants can play a pivotal role in the achievement of successful outcomes by the interns. One key component of an "effective and pedagogically sound internship experience is that it is based on the triangulation commitment of all stakeholders involved" (Zopiatis \& Constanti, 2012, p. 44). To better facilitate a pedagogically sound internship program, the data will be triangulated to evaluate the relationship between experiential learning and the achievement of KSA's. The study will evaluate the intern's perception of their leadership skills before and after their experience, as well as the perception of their leadership skills by the internship supervisor. 


\section{Sampling Procedures}

One of the sixteen types of purposeful sampling identified by Patton (1990) is convenience sampling (Hoepfl, p. 51). Purposeful sampling seeks information-rich cases which can be studied in depth. The sampling procedure that will be used for this study is convenience sampling, a form of purposeful sampling. This is considered a theoreticalpurposive approach to sample selection which is consistent with the constructivist approach to research. This approach will capture the information that emerges from the sample and the variations and saturation that exists within the patterns of data that emerges. The results may provide data on the internship experience common to all of the interns. The convenience sampling process should be sufficient to gain an understanding of the variety and depth of the data and to support the results of the research.

\section{Design for the Study}

The qualitative approach to research is best suited to examine the experiences and perceptions of the participants and to further explore the leadership competencies that can be acquired through experiential learning. As Merriam (1998) states, qualitative research is "designed to inductively build rather than to test concepts, hypotheses, and theories" (p. 45) and this study will build upon the concept that experiential learning is a way for students to achieve skills that are valuable to the continuing success of the hospitality industry. The prominent characteristics of qualitative research design that will be used as the rationale for the approach to this study include: the ability to gain more in depth information that may be difficult to convey quantitatively; the ability to use natural settings as the source of data; the researcher in this study is the human instrument for data 
collection and can pay attention to the uniqueness of each case; and qualitative research has an "emergent" nature as opposed to a predetermined design (Hoepfl, 1997). For practical purposes, the qualitative approach is wise because no valid, appropriate quantitative methods seem feasible to measure the outcomes achieved in the experiential learning process or to measure the reflection provided by the individual participants (Mertens, 2005).

The study will use several forms of data that continually emerge in qualitative research. Interviews will be a primary source of information. The perceptual information that will be used in this study will be obtained primarily through the interview process. Observations will be made by the supervisor of the intern and documentation will be developed in the form of an evaluation. The supervisor's evaluation will be based on several criteria, including the observations of all of the participants in the internship process. A critical incident report by the intern will also be part of the data collected that is consisted with the qualitative design approach.

The collective case study approach is also appropriate for this design. Multiple case studies will be explored from one hospitality management program. The multiple case study design uses the logic of replication which allows the researcher to replicate the procedures for each case (Creswell, p. 74). The use of multiple cases from multiple sites will help to illustrate the individual perspectives on the research.

\section{Rationale for the Research Design}

The interview format was chosen over individual surveys of the population for this study. Though interviewing may sometimes require training by the interviewer (Fink, 
2009, p. 9), the individual's perceptions, versus opinions, can be better managed. The interviewer can explore more areas with the interviewee, make eye contact and observe body language, and in the case of phone interviews, the interviewee may be more comfortable exploring more areas for discussion in the physical location most comfortable for them. The process of interviewing the intern at the completion of the internship allows the intern to reflect on the experiential learning process. A study completed on hospitality management students suggests that a positive relationship exist between leadership skills and practices, and students who reflect on self-behavior and actions (Arendt \& Gregoire, 2008). The ability to reflect on one's actions, and change action based on reflection, may be a valuable leadership development tool.

In qualitative research when interviews are the primary tool for data collection, perceptual information is the most critical of the information needed (Bloomberg \& Volpe, 2012, p. 106). Perceptual information relies on the interviewer to uncover the participant's experiences and how the experience may have shifted their attitude or changed them in many ways (Bloomberg \& Volpe, p. 106). The interview process is a way to effectively address the research questions and provide the depth and breadth of information that is being sought from the interns in this study.

Critical incident reports allow for the uncovering of perceptions not revealed through the interviews (Bloomberg \& Volpe, p. 122). The report may allow for the participant to probe assumptions and reflect on the incident. The critical incident report is a valuable qualitative research method because it is based on a descriptive and inductive approach to data collection. The reports should provide the researcher with a tool to assist in corroborating the interview data. 


\section{Data Analysis}

The data will be analyzed based on horizonalization and clusters of meaning (Creswell, p. 61). Horizonalization allows the researcher to build upon the data collected from the research questions and identify significant statements provided by the participants that will provide understanding of their internship experience. Clusters of meaning can be formed to identify central themes derived from the clusters (Groenewald, p. 19).

\section{Data Collection Methods and Procedures}

The process of data collection is described by Creswell as a "circle" of interrelated activities... process of engaging in activities that include but go beyond collecting data" aimed at gathering good information to answer emerging research questions (Creswell, p.117). Data collection can be divided into information sources: people (surveys and interviews), observation of events and physical documents (products such as student portfolios), assessments (tests) and various forms of documentary evidence, such as evaluation reports (Mertens, pgs. 343-344).

The use of multiple methods and triangulation is critical in attempting to obtain an in-depth understanding of the cases under study. This strategy adds rigor, breadth, and depth to the study and provides corroborative evidence of the data obtained (Creswell, 2007; Denzin \& Lincoln, 2011). The methodology for data collection for this study will be from multiple sources. Primary data will be collected in the form of interviews, observations, and document review. Interviews and observations are central to the design approach in qualitative studies. Interviews with the interns will be audio-taped and based 
on an interview protocol. The interview protocol will consist of open-ended questions designed to understand the perceptions of their leadership skills before and after their internship. The questions are a narrowing process of the central question to sub-questions (Creswell, p. 132). The topics of questions used as the interview protocol will be semistructured. There will be a set of open-ended questions presented, but the interviewer will have latitude in exploring perceptions, opinions or values, knowledge and feelings about the leadership learning process. As a second option, when direct access is not practical, telephone interviews will be conducted.

The data collection method of observations will be used in the form of critical incident reports and supervisor evaluations. A critical incident report is a product of critical incident analysis. It is suggested that critical incident analysis has value and is appropriate for developing interpersonal skills and self-awareness. Critical analysis has its roots in industrial and organizational psychology and it has been used in measuring typical performance, training, proficiency, and in determining motivation and leadership attitudes (Butterfield, Borgen, Amundson, and Maglio, 2005, p. 477). Critical analysis enables students to draw upon experiences and make sense of them, facilitating learning from practice (Parker, Webb, \& D’Souza, 1995). Critical incidents reports provide the intern an opportunity to learn by example, a technique designed for collecting direct observational data, collected from specific events, of human behavior to facilitate problem solving. Critical incidents are especially useful in exploring specific, situationally relevant aspects of managerial behavior (Yukl, 2006, p. 62).

The supervisor for each intern participant will provide an evaluation of the competencies achieved by the intern at the completion of the internship. This evaluation 
will be based on a 5-point Likert Scale that will assess degree of the KSA's achieved by the intern, using satisfactory to excellent as a range of measuring performance. The response by the experiential learning supervisor is a vital component in designing the internship experience and evaluating the learning outcomes and skills achieved by the intern. As the supervisor is experienced in the hospitality management position that they hold their evaluation will provide important data regarding the intern's leadership competencies and knowledge.

The data collected will support the research questions posed and are designed to lead to textural and structural descriptions of their experiences. Through triangulation, the collection methods and procedures chosen will provide an understanding of the experiences common to each individual.

\section{Data Analysis Procedures}

Qualitative data analysis can be defined as "working with data, organizing it, breaking it into manageable units, synthesizing it, searching for patterns, discovering what is important and what is to be learned, and deciding what you will tell others (Bogdan, \& Biklen, 1982, p. 145). The data analysis for this study involves preparing and organizing raw data, then reducing the data into emerging themes using a coding process. Some of the data for this research will be presented in the form of figures, while the majority of the data will be represented as a discussion. The inductive analysis approach

will be used. This will allow for critical themes to emerge out of the data and for placing raw data into logical categories and analyzing and interpreting the data to inform the research question. 
Elemental coding methods are the primary approach to qualitative data analysis. The specific elemental coding method that will be used as a foundation for this analysis is descriptive coding. This type of coding will be used for several reasons. First, it is useful for novice qualitative researchers because it helps organize the data at a basic level and assist with organizing the study. Second descriptive coding is valuable for research with various forms of data such as evaluations, diaries, correspondence, and interviews. Finally, this type of coding will assist with providing the reader with the description and interpretation of the data.

The analysis process will also include classifying. Classification will allow for the establishment of themes and patterns from grouping personal experiences and statements provided into meaning units.

\section{Issues of Quality}

The information presented in this research must be established as trustworthy and credible. Several standards have emerged to judge the quality of qualitative research information and to establish the reliability and validity of the data. The standards used by constructivist researchers to address issues of quality with qualitative research include: credibility, transferability, dependability, and confirmability (Mertens, p. 253).

The criterion of credibility suggests whether the findings are accurate and credible from the standpoint of the researcher, participants and the reader (Bloomberg \& Volpe, p. 124). Credibility parallels the criterion of validity in a quantitative study. According to Polkinghorne (1989) validation refers to the notion that an idea is well grounded and well supported (p. 57). He posed five questions that researchers should ask 
themselves when addressing validity. The questions address the interviewers influence over the contents of the participants' descriptions, the accuracy of transcription, and the ability to account for specific content and connections in the examples of their experiences and perceptions (Creswell, p. 215). A pilot test of the interview protocol questions will be conducted to test whether the questions will provide the information needed. A pilot test can quickly reveal whether the content is understood by the participant and it can help the researcher eliminate any potential areas of difficulty. A pilot test of the face-to-face interviews will also be conducted. Consistent feedback from the interns during the internship, along with interviews post-internship, will also be used to establish credibility.

Triangulation methods may be used from the multiple data points completed from the research. This process will allow for corroboration of data from the various sources and for support of emerging themes and theories. Assuring dependability will require maintaining protocol for the research process and subjecting the process to auditing. Dependability of the research may be addressed through establishing if the results can be subjected to change and instability (Creswell, pg. 204). Transferability, a criterion of trustworthiness, can be established by the degree of shared experiences among the interns (Bloomberg \& Volpe, p. 113). Though the information gained from the descriptions provided by the interns may not be generalized across all participants in a hospitality management internship, the reader may find that this information may apply to other internship sites or research with similar processes and contexts as judged by the reader. 


\section{Limitations of the Research}

The primary sampling procedure used in this study is convenience sampling. Though this type of sampling procedure provides a readily available population, the procedure has limitations. This research will only be conducted on hospitality management interns at one institution. A wider sample of that population, over a longer period of time, would further support the ability to generalize the results. This study takes place at a public university in the mid-west of the United States. The study is therefore limited by the population of the geographic area and may reflect the values and behaviors conducive to the geographical region but not necessarily of interns in all geographical areas. This research may still apply to private universities in other geographical locations, as well as have application in the hospitality industry overall.

Another key limitation of this study is the issue of subjectivity and potential researcher bias. The researcher is the internship advisor for the hospitality management internship program and the director of the hospitality management program. The researchers' role with the internship participants may introduce concerns regarding assumptions and perceptions and how the research is framed. The researcher will address the possible concerns of bias and subjectivity during data analysis by coding all interview transcripts blindly to not associate any material received to a particular individual.

The study is limited by the boundaries of time and constrained by the possible lack of depth of each case, or variations on the consistency of how much information each participant provides on their experience.

The study also does not address questions regarding the level of achievement of specific KSA's by one student compared to another. More research is needed to examine 
if the attainment of particular KSA's are predicted upon other factors, such as academic grade point average, personality assessments, and test scores, which may further influence or impact individual success in the experiential learning process.

This research should provide valuable insight into how hospitality management programs can prepare students as future leaders in the industry and help bridge the leadership deficit that exists. The ability to design, or redesign, curriculum in the higher education system may not be immediately feasible or practical. A hospitality management program would have to be open to the structural and philosophical change that is required to implement an experiential learning program into the system, and have the resources to achieve those goals. More data would be valuable on how changes can be realistically implemented within current higher education structures.

\section{Description of the Researcher}

The researcher of a qualitative study has an obligation to several concepts that are conducive to designing an effective study. Trust and credibility are important qualities of the researcher. Strauss and Corbin (1990) refer to "theoretical sensitivity" as a way to measure the researcher's skill and readiness to conduct a qualitative study (p. 42). Theoretical sensitivity is an awareness of the subtleties of the data, the ability to have insight and to give meaning to the research. It also refers to the ability to separate what is pertinent from what isn't. This research will require theoretical sensitivity to the data. The researchers experience in the hospitality industry will assist in describing each internship experience from a professional perspective. The researcher may also provide feedback to each participant throughout the data collection process regarding 
their internship environment in order to maximize the experiential learning process. The researcher should be sensitive to the position they have as the researcher and internship supervisor and to any bias that may present itself during the research process.

\section{Ethical Considerations}

The research will be conducted under the informed consent of the participants. Participation in this study is not expected to cause any risk greater than those encountered in everyday life. There are no adverse consequences (physical, social, economic, legal or psychological) of an intern's decision to withdraw from the research at any time. In the event of withdrawal, the intern will continue the internship but their data will not be used for the purpose of this study and the data will be destroyed. Participation in the study is strictly voluntary and the intern may refuse to participate and/or discontinue their participation at any time without penalty or prejudice. The intern will also be informed that participation, or a decision not to participate, will in no way affect their grade in the internship course. The interns' identity (individual names and academic information) will remain confidential. The interns will be coded by gender and each one will be identified by a letter only, which will not represent their real name. The raw data will be filed and stored by the researcher off-premises from the research site and protected from unauthorized individuals. 
Summary

The data that is collected and analyzed will provide an understanding of the perception of knowledge, skills, and abilities that are achieved by interns during their hospitality management internship. Qualitative case study analysis was used because the goal of this research is to understand the bounded social phenomena that exist among multiple interns during a hospitality management experiential learning experience. Three data collections methods will be employed, including interviews, critical incidents reports and document review from observations. The analysis, conclusions and recommendations of this research will aid in bringing clarity to the role of experiential learning on leadership competencies and how experiential learning can be effectively integrated into a hospitality management curriculum. 


\section{Chapter IV}

\section{Presentation of Findings}

Chapter four discusses the qualitative analyses of the data collected for this study. The purpose of this study was to understand how interns perceive the development of their leadership competencies during their hospitality management internship. The study also sought to understand the internship supervisors' perceptions of the interns' competency development and overall performance. This data was gathered through convenience sampling of students completing their internship in a hospitality management program at Southeast Missouri State University. The information in this study will: 1) inform individuals who direct internship programs on the theory and practices behind the concept of experiential learning and internships; 2) provide educators with information that assist in designing and implementing hospitality management internships; 3 ) provide an understanding of how interns and supervisors perceive the leadership competencies that they gained during the internship experience; and 4) help identify how experiential learning can be best integrated into hospitality management programs.

Most hospitality management programs have emphasized the importance of experiential learning through internship opportunities (Lam \& Ching, 2006). This type of work-integrated learning provides participants with the ability to develop specific competencies, abilities, and transferable skills. From the student's perspective, an internship provides a valuable learning experience and enhanced employment opportunities (Cook, Parker \& Pettijohn, 2004, p. 181). The internship provides students 
the opportunity to work with industry professionals and observe first-hand the processes involved in their prospective future job. There is increasing awareness among graduates that an internship may enhance their ability to obtain the job they want in the industry.

Internships also appear to help students relate their classroom experience to the work experience. Ju (1997) notes that internship programs provide students with the opportunity to test their career choices while they are still in college. A well structured internship can provide a positive experience for the participant and enhance the likelihood that the student will strongly consider the career path.

\section{Participant Demographics}

The participants to this study consisted of six interns completing a hospitality management internship at various locations and five supervisors who evaluated the interns on the competencies that they gained during the internship. The following is a brief description of the type of location that each intern has selected and a personal statement from them as to what their expectations are of the internship experience:

Intern A completed her internship at a national chain casual-dining steak house in Cape Girardeau, MO. Her internship goals included learning all facets of restaurant operations, while working primarily in the front-of-the-house. She states one of her objectives as: "I need to learn how to pay attention to politics and how to communicate. I want to work on my communication skills as well as with my customers and fellow coworkers. Hopefully, I will be able to form personal relationships with the regulars too." 
Intern B completed her internship at a not-for-profit organization located in Portageville, MO. Her responsibilities included participating in management and leadership learning objectives, specifically human resources related, and coordinating events and meetings for the organization. She identified her internship learning objectives and goals as:

"I need more experience with business development of hospitality. I will focus on how managers function in their daily routines. I wanted to learn how business is set-up (i.e. the organization chart) and what people do. I think this is applicable across all segments of hospitality. My personal goals and opportunities of this internship are to gain an insight into what takes place in real offices: functionality, organizational flow, empowerment, human resources responsibilities and performance, leadership, technology skills, accounting skills, communications skills. I feel that combined with my studies at Southeast Missouri State University in Hospitality Management, these skills and performances are essential to experience for a future employment of my major. It will give me a broader outlook of all my studies in action and can be applied to most any type of occupation."

Intern C completed her internship at a Bed \& Breakfast in Cape Girardeau, MO. Her responsibilities included learning all aspects of operating a small lodging facility. She identified the following internship learning objectives and goals: 
"I want to learn the ability to multi-task, to be open to learn how to do new things, ability to adapt to change and friendly to guests, providing excellent service so they enjoy their time. What I expect to learn is what it takes to run a bed and breakfast. I wanted to learn this because I was thinking of maybe owning my own bed and breakfast, maybe one house with 3-5 rooms. Another objective I would like to learn while I'm there is more about events and the event contracts."

Intern D completed her internship at a major amusement park in Orlando, Florida. She identified the following internship learning objectives and goals:

"There are a few skills that I expect to gain. I expect to gain knowledge of how to interact with guests. I additionally wish to gain knowledge in how to operate rides and follow safety guidelines to insure that guests have a safe and fun day in the parks. I also aim to gain skills in how to effectively manage crowd control. I wish to gain knowledge in what it is like to work for a Fortune 500 company. I have known a few people who did the program and none of them have had any issues with obtaining jobs after completing their internships."

Intern $\mathrm{E}$ is also a graduate of the Accelerated Culinary Art Program at the Culinary Institute of America. She completed her internship at two fine-dining restaurants in Cape Girardeau, MO. She identified her internship learning objectives as: 
"I want to learn what to do in preparation of opening a restaurant. Learn from others how to run a successful business."

Intern $\mathrm{F}$ is a citizen of Japan. She completed her internship at a local restaurant in Cape Girardeau that focused on international cuisine. Her internship learning objectives and goals were identified as:

"I expect to gain the knowledge and skills (in) the systems of restaurant and service. I am expecting to give my full contribution to the organization by putting my full effort to improve their business as long as I am working for them. I think that I can give information about Japanese food. However, I think a lot of things cannot be learned if I do not actually work at it. Therefore, I think that (the) internship is (a) very good opportunity before getting job. There are a few differences between people who have done internship and people who have not done it, and of course people who have done it is advantaged. Finally, I could make many new friends through the internship."

The interns identified several skills and competencies that they expect to gain and many of those skills have been identified as desirable hospitality management competencies. The type of location where the interns conducted their internship differed, thus the range of exposure to leadership skill development varied for each intern. The interns overall perception of the internship experience provided an understanding as to how the experience aligned with their expectations. 


\section{Research Questions}

The research questions were designed to understand the leadership competencies achieved by students during their hospitality management internship. Integral to developing leadership competencies is the ability to understand how interns learn, and particularly how they shape learning in an experiential learning environment.

The research questions were also designed to understand the perceptions of the supervisor or manager of the intern's skill development. The perspective of the stakeholders involved in the experiential learning process - interns and supervisors or mentors - assisted in furthering the process of developing leadership competencies.

The question of how well students perceive the hospitality industry competencies, standards, and their achievements, provided an understanding of how the experience impacted them individually. The students perceived the competencies as realistic, operational and achievable, and thus may believe that they can realize career success. The data also indicated that a number of the students had mixed or negative feelings about the experience and what was learned, which is an outcome that can lead to more questions about variables and other factors that may impact those perceptions. Their reflection on the experience helped to understand how significantly an internship can change their lives and help them gain the knowledge that they will need to become leaders of the future. To accomplish this study the following research questions were addressed:

1. How do interns perceive their growth as a leader during their hospitality management internship experience?

2. What are the interns' perceptions of their communication skills? 
3. What are the interns' perceptions of their interpersonal skills?

4. What are the interns' perceptions of their information technology skills?

5. What are the interns' perceptions of their marketing skills?

6. What are the interns' perceptions of their financial management skills?

7. What are the supervisor's perceptions of the leadership competencies and knowledge gained by interns during the internship experience?

Five major findings emerged from this study:

1. The majority of the participants (5 of $6[83 \%])$ expressed significant participation in analytical, financial and problem-solving activities, or "leadership" competencies, during their internship experience.

2. The majority of the interns (5 of $6[83 \%]$ ) cited a lack of opportunities to develop technical and marketing skills. Only one cited limited exposure to gain skill development in those two areas in the organization.

3. All of the interns identified communication, teamwork, employee and customerrelations, or interpersonal competencies that they learned during their internship experience.

4. All of the interns identified specific leaning experiences that were most significant to their overall experience and the changes that were required in their lives to accommodate full participation in the internship experience.

5. The majority of the interns' supervisors (5 of 6 [83\%]) provided favorable feedback regarding the interns' leadership development, while also identifying areas for their future development. 
The following is a discussion of the findings with supporting discussion of each finding. The researcher's goal was to gain an understanding of how students in a hospitality management program gained leadership and management competencies during their internship experience. The interns provided an initial brief statement of their personal definition of leadership competencies, or what a leader is to them. The process of defining leadership competencies allowed them to identify and discuss their own skill development. The interns expressed their characterization of a leader in the following terms:

Motivating, lead by example, doing their best, puts forth the effort, having knowledge but doesn't need to know everything - need to know how to function. (Intern A)

A leader has honesty, respect, fairness, understanding, equality, effectiveness, knowledge of their product \& company, goal setter. (Intern B)

A leader has the ability to communicate well with others, manage a group of people to make sure that they are getting the right task done for that day correctly, prioritize different task that need to be done, dependable, honest, hard-working, and intelligent. (Intern C)

A leader has the ability to delegate tasks, communicate with a variety of different people in addition to manage a group of people. I have learned that leaders who have good relationships with the employees are more likely to have the employees listen to them verses the leaders who are not well liked by the employees. (Intern D) 
A leader has vision, is a team player, hard worker, can delegate (to) members of the team, and most importantly someone who is a good communicator. I still believe that leaders should have vision and be able to communicate that vision to others; however, I believe a true leader is someone humble enough to teach why they want things done that way...someone who leads by example rather than just commands. (Intern E)

A leader is someone who puts workers together, develops worker's abilities, is relied on and relies on the workers. (Intern F)

The interns' initial statements of leadership characteristics revealed that the interns have some understanding of the skills and abilities that are known to characterize effective leaders. They identified several skills that are essential for effective leadership such as: motivating, having vision, ability to communicate, team oriented, having industry knowledge and having the ability to lead. The interns' responses indicated that as they started their internship they have an overall understanding of the definition of leadership, however, their internship allowed them to see how these skills are developed and operationalize in a hospitality management organization. Defining leadership competencies from the start of the internship allowed the interns to identify the leadership development opportunities and achievements throughout their experience.

Finding One: A majority of the interns (5 / 6) identified analytical, financial and problem solving as competencies that they observed and learned during their internship experience. 
The primary finding of this research is that interns were able to express management and leadership skills and competencies that are essential knowledge, skills and abilities (KSA's). This finding is significant in that each intern identified learning skills that are aligned with the future-oriented competency models developed with the hospitality management industry in mind.

Based on the intern's descriptions, there were opportunities to learn analytical, problem-solving and financial skills. The interns expressed their analytical and strategicthinking skill development in the following ways:

I'm constantly prioritizing, analyzing a situation. Sorting things out in my brain identifying what's important. I can analyze a table and guest...better strategize about how to approach them. I try an instant psychological profile, identifying what to suggest (food \& beverage). How they're dressed is important in analyzing a customer. (Intern A)

I think I have improved my strategic thinking skills, especially when I have to seat guests for the attraction. I have to know which way is going to be the best fit to get them onto the boat, keep the party together, while loading the boat in an efficient manner. I also have to analyze when it is a good time to close or open up queue space. I have to take into account if there is a parade going on or if another attraction has gone down and adjust whether or not my attraction is going to have more or less guests coming to ride it. (Intern D)

One intern emphasized that she already possessed analytical skills, however she indicated the she used these skills to analyze data in more detailed and repetition in the internship:

I already had analytical and strategic thinking skills. I'm able to prioritize, categorize. I'm highly organized. I used these skills (in the internship). I dissected data six times, doing several weeks of analytical work. Required focus on lots of data details...I never knew that one sheet of paper could be dissected so many times. My husband always said I could analyze something to death. Guess that is me. (Intern B) 
Two of the interns discussed problem-solving skills that they used when presented with customer-service related situations. Both interns identified similar operational challenges and expressed their reactions and solutions:

I would describe my ability to think about situations analytically and strategically as pretty good because I like to think that way about different situations and about the possible problems, so I can help prevent those problems from happening. An example from my internship where I used problem solving skills is when the guys were on vacation. I had to figure out how to check guest in because I had to do it for the first time by myself so I had to use problem solving skills to figure out what I had to do. I didn't know how to use the credit card machine yet. I had to find the papers that "J" told me about to be able to figure out how to perform the different functions that the credit card machine has on it. So I found the papers and read it and found out how to use the credit card machine. (Intern C)

The first problem I faced is that the worker in the dining room was only me even though it was the third day since I started to work there. Since it was my third day to work, I did not know how much is the buffet exactly for students or loco (local) residents and how to use the electronic cash register and credit card machine because I was told I do not need to know how to use it yet. Most customers pay their bill by credit cards. However, since I did not know how to use the machine, I asked customer whether they have cash or not. Some customers did not have cash but their friends paid for them. Fortunately, all customers could pay in cash. I had to open the cash register with the use of force. About one and half hours later from the opening time, the employer came back to the restaurant. Then, I asked her how to uses it, and finally I learned it. (Intern F)

Intern $\mathrm{F}$ also discussed how she realized that the other employees were "thinking for themselves", which is something that she had to observe happening in order to learn it. She discussed a situation where the food items at the buffet had run out, but because she had not been told to order more food from the kitchen, she didn't take the initiative to solve customer-service related problems:

The lunch time at the café is busy. I noticed that there (was) almost no foods on the buffet table. However, I had never ordered food (from the kitchen) because I did not know I should do that. Sometimes one cook comes to the dining room to check the amounts of remaining foods. Therefore, I thought that I do not need to order them. When the employer came back to the restaurant, she said to me "Why are there no 
food and I why did you not order it?" Actually, I thought that why I should do that even though nobody has not told me to do it. However, of course I could not make an excuse. I thought that I do not know why I got the warning. However, I have really cared about the amounts of remaining foods since that day. I think that it was a good experience for me. I know that I relied on the other workers when I worked with them because I think they checked the amounts of remaining foods and ordered it all. I should not have needed to be told to order it (the buffet food). However, I realized that the other workers did not need to be told, they acted by thinking by their selves. Therefore, I feel I was selfish and I should pay attention more even if it is not my area or I have not learned it.

Intern B indicated that she already had problem-solving skills; however the internship experience required her to change her approach to problem-solving and learn how to adjust her skill-set to a new interpersonal situation:

I used problem solving skills - already confident in that ability - but had to take different approaches to problem solving. Generation gaps challenged my problem solving skills. Many of the employees were younger than me and I had learned to solve problems with more authority. I have worked in a hierarchy. I learned situational problem solving. Learned to work with defensiveness - things were "touch and go" with certain age groups. I had to understand and focus on what was important and a priority for different age groups and situations. (Intern B)

Three of the interns discussed their experience with financial situations. Having knowledge of financial analysis and management skills has been identified as one of the KSA domains for hospitality management success. Kay and Moncarz (2004) identified several financial management skills that are perceived to be important, including controlling costs, managing cash flow, planning and budgeting, and having knowledge of operational and financial analyses and leveraging. The interns expressed their learning opportunities with financial skill development in the following ways:

I personally learn the cost of items to better solve financial issues with customers learned deposits, bar drawers, labor report, daily sales report, and problem solving with money. If I'm short $\$ 20$, I need to find out where I'm short. Sometimes the manager helps with that. (Intern A) 
My financial skills included learning how to allocate money from the budget funding from a limited budget. Financial management situations involved making decisions about how to allocate limited financial resources. A formula was used to assist with allocation. (Intern B)

I learned about the importance of financial stability at restaurant $\mathrm{C}$. They started the restaurant only after they had a strong relationship built with their catering customers. This allowed them to continue using catering as the main income source, which took pressure off the restaurant. At AB I learned how closely you have to watch the spending of your startup costs and save the revenue made in sales. It was a valuable lesson to learn what can happen when you spend too much money in the beginning and do not have steady income flowing into the business. (Intern E)

The path to gaining financial skills was observed in a back-of-the-house situation for

Intern E. She was able to understand expenses in the restaurant based on a cost-benefit

analysis that she discussed regarding their resources. She states:

Restaurant $\mathrm{C}$ does not have a mechanical dishwasher. Everything from pots to full sheet pans, dishes to bus buckets is hand washed by one guy. Recently Chef D asked the dishwasher to dry everything with paper towels rather than (dish) towels. It doesn't make sense to me to waste paper towels, which cost a lot of money, rather than use a towel that has already been purchased and we launder at our facilities. I believe it was a very wise investment for the owners to have a washer and dryer on the premises. At my last place of employment we hired a company to wash towels and aprons; it was a huge expense.

This finding indicates that the interns experienced situations where key leadership skills were gained or enhanced. The interns discussed situations where problem solving, analytical abilities and financial and technical skill were gained on various levels. Kay \& Moncarz (2004) have identified these competencies as part of the most recognized skills for hospitality leaders. The interns highlighted how they improved their strategic thinking skills, solved operational problems with little to no supervision, and gained first hand experience with financial responsibilities. These particular set of skills are among the collective KSA's ranked most important for hospitality management success. 
Finding Two: Kay and Moncarz (2004) have identified marketing and information

technology, or technical skill, as an essential skill for hospitality managers and

leaders. However, the majority of the participants in this study indicated that

though they had some exposure to those areas during their internship, there was not as much of an opportunity to develop these skills (p. 64).

Intern A indicated that "practice and repetition has improved my technical skill" and Intern B stated that "Excel (software) was the most important information technology skill learned". Both expressed shortcomings in their internship locations and their personal competence regarding technical skills. Intern A said "I see a need for more technology (in the restaurant) because there are more servers than cash registers.” Intern B stated "my Excel experience is not one of my strongest assets. In the future, I would like to take another Excel class to get better at it. I strongly believe Excel needs to be included in our (hospitality management program at SEMO).

Other interns spoke of their experiences with technical skill development, which included using the internet for resources and research; having knowledge in reservations systems; and a working knowledge of the product-service (Kay \& Russette (2000), (Kay and Moncarz (2004). They expressed their lack of growth in this area as follows:

I did not improve much on my technology skills. I used a few new machines and different equipment from time to time but I would not say my technology skills made a drastic improvement. (Intern E)

My information technology skills are about the same as before I started my internship. The one area I have gained some knowledge is in using the company intranet. This is what we call the hub and it contains our schedules and anything regarding the company that I may have a question about. (Intern D)

Some technical skills I have learned are how to use their online reservation system called Webervations. With this I know how to look at the availability of rooms if people call with a reservation, and I can also look and get people's reservations that they make online on the website. Another technical skill I have learned is Word 
Press. This is how you create and update the web page with changes. So I learned how to use that. But I think it (my technology skills) could definitely be better. My internship did not really enhance those skills. I felt like I was the one teaching other people the technology skills. (Intern C)

The majority of the interns ( 4 of 6 [66\%]) did not identify marketing skills, one of the perceived important KSA domains developed by Kay and Moncarz (2004), as an objective or goal for them by their internship supervisor. In most cases the interns expressed very little exposure to opportunities to develop those abilities related to marketing such as; developing promotional and public relations strategies, promoting and upselling products and services and establishing achievable marketing goals. Intern A responded to the question about managements approach to marketing as "they don't say you need to "market" - the word upsale is used", which suggests that a formal approach to marketing products and services was not utilized. Overall the intern's responses indicate that their perspective internship locations did not have marketing and sales skills development as a goal for them, or the interns were not able to participate in that function during the scope of this particular research. They expressed their experience with marketing efforts succinctly:

I have gotten better at talking about the different products and services offered by the company but other than that my marketing skills really have not changed. (Intern D)

The owner also has me make flyers about special events that they are going to have and he has me put them on Facebook since he doesn't know how to use Facebook. This is some of the only marketing we used. (Intern C)

Intern $\mathrm{E}$ observed failures in marketing and learned the value of marketing through comparison of both of her internship locations: 
At AB I watched a new restaurant try to market to keep sales up. At $\mathrm{C}$ it was interesting to me that they did no marketing at all but relied on word of mouth. I learned how important marketing can be to different demographics. The higher income families are not looking for a deal, but rather a night out to treat themselves. $\mathrm{C}$ took advantage of this by catering meals for the medical field and relying on word of mouth by doctors for their restaurant. $\mathrm{AB}$ marketed by putting flyers on cars that were parked in the church parking lot, advertising to come by for Sunday Brunch. To me this was tacky and was not thought through. (Intern E)

\section{Finding Three: All six interns identified interpersonal skills as competencies that}

\section{were gained during the internship experience.}

Interpersonal skills are one of the domains and functional areas of management and leadership. Interpersonal skills that are essential for management development include: Oral communication and listening skills, employee-centered abilities, team work, creating positive relationships, customer-centered relations and resolving conflicts with a win-win-resolution approach. The development of interpersonal skills by the interns resonated positively in their responses. All six of the interns described opportunities to develop their interpersonal skills with employees and customers, as well as the challenges they encountered with their interpersonal goals. Most of the interns described their interpersonal skills as having improved during the internship. On this finding, Intern A commented: "My interpersonal skills have changed. I tend to talk to people more often and I can tell more often if a person is in a good mood or a bad mood and I can adjust my response to their questions." Intern E discussed what she learned regarding connecting to people:

I learned to keep a more open-mind to people and not be judgmental of how people live their lives. I have always been able to take to people but through my internship experiences I can now connect to people easier. 
Overwhelmingly, working with teams was identified to be an area of

importance within the internships. Two interns discussed their comfort in developing

their team-oriented skills and how beneficial team-based activities were to their learning:

I feel very comfortable working in team situations because that is what the majority of my job consists of. It takes a team to get the boats loaded and unloaded on time to keep the river moving. Each of the employees count on one another to make sure that we move spots in a timely manner and to make sure that the attraction stays running. (Intern D)

I found the teams I worked in to be very beneficial to my learning. Without the people I worked with supporting, guiding, and teaching me I would have not been successful in this field. I learned that building relationships with those that work with, for, and under you, can be the most important factor of the success of a business. (Intern E)

Intern A expressed her skill in leading a team and her ability to embrace larger, more complicated situations:

I work well with the team. Often work with another server. I usually lead the team because I want everything so right. I know my strengths and what I want to accomplish. At first I was afraid of large groups, now I prefer them. I give smaller tables to others now and take on larger, complicated issues. I'm able to simplify.

There were, however, a few barriers with team-building and employee-centered encounters. The majority of the interns stated how they overcame personality challenges with employees to create better communication. Some of the barriers that the interns worked through are:

Personality conflict with an employee was a barrier to learning. Intimidation was initially a problem. I had to overcome, stand firm, use facts to communicate with this person. (Intern B)

At one point I felt my partner at my station was stifling me so I would need him to continue doing certain things. I eventually talked to him and expressed that I was not there to take over his space but rather to learn so I could eventually do it by myself. I feel that being open to communicate to people is very crucial, especially in this field when pride and assertive attitudes may get in the way. (Intern E) 
The barriers to my leadership development would be lack of trust by other employees. They do not think that I have been here long enough or have enough knowledge to actually know what I am doing. I had to prove that I am not going to mess up whenever they give me something new to do. (Intern D)

I am not satisfied with one thing. It is that we, servers, wash dishes and other tools that are used by the cook when we do not have any tasks in the dining room. However, the cook do not wash them even when he has nothing to do, and he smoke tobacco outside and sit on the chair. I think that helping each other is very important at work. (Intern F)

One intern made a suggestion regarding the management's approach to communication with the employees. Intern D suggested that management consider changing the communication process used by employees to talk to their managers:

The one issue that could be changed in general management is the communication between the managers and the workers. While the workers are encouraged to talk to management if they have a suggestion or a complaint, there is often an issue with meeting with them face-to-face to convey the issue. There is often confusion as to which manager is available to talk to, since they work three different shifts during the day. If a worker is lucky they may be able to catch up to their favorite manager during their free time. To improve this situation I would make the managers more available to the workers, whether through open door office hours or just have them more visible at the attraction throughout the day.

Several of the interns discussed incidents that involved correcting undesirable behavior with either employees or customers. The Lodging Internship Competency Model proposed by Solnet, D. et, al, (2009) suggests that there are factors that will impact competency development during the internship. Assessment and reflection by the interns of the interpersonal or human-resource related skills is one of those factors. Intern A made observations about the manager's behavior that she perceived to be unprofessional and undesirable. She assessed the interpersonal skills displayed by a manager suggested a positive-reinforcement approach to employee-related incidents: 
At the restaurant there are assistant managers who are called "key holders". When " $\mathrm{K}$ " or " $\mathrm{C}$ " are keeping things together in the back of the house, they are in the front of the house taking care of what " $\mathrm{K}$ " would normally be doing. There is one key holder in particular that I can tell this is his first job where has had any authority over a group of people and it goes to his head. We're told to maintain a professional environment with our guests and our coworkers. However, he tends to cuss quite a bit and complains whenever anyone asks him to do anything. He uses negative reinforcement and always points out what we do wrong. I'm fine with being criticized over things I do wrong but whenever I hear him say "these God-damned new people, I swear', I'm going to have a problem with him. I've heard complaints from other servers as well so I'm not the only one. I don't necessarily want to see him fired; I just want him to respect the rules, his coworkers, and use more positive reinforcement rather than constantly being a "negative Nancy".

Intern F highlights how her manager was "being nice" to employees when their behavior suggested a need to be less lenient. She identified situations where other employees were "in the kitchen replying to text messages, outside smoking tobacco when their help was needed inside the restaurant, and calling in sick when they knew that would leave only one employee to work the dining room". She offered suggestions for the owner on this problem:

I do not know why the owner hires these workers. However, I think she does not let them quit. She knows there are some problems but she does not say anything. She is very nice and kind but sometimes it is wrong as a manager. I think that she should make them change or try to quit them.

Given that all of the interns gain some experience in their interpersonal skill development, it was apparent that this competency was recognized by each intern as valuable. Most of the interns mentioned that they had improved upon this skill as well as faced challenges in the process. 
Finding Four: All of the interns (6 /6) identified specific knowledge, skills or abilities gained and learning outcomes achieved upon completion of their internship. The interns also overwhelmingly indicated that changes in their personal lifestyle and daily lives were required to allow them to fully participate in the internship.

There was a notable consistency with the interns in their discussions about the changes that they had to embrace to complete the internship. Developing adaptation skills and adjusting to the change that was required to complete their goals and objectives were mentioned by almost all ( 5 / 6) interns. Intern D expressed the degree to which she had to adapt by stating: "So far the first three weeks of my internship has required a gigantic learning curve." Their comments illustrate the impact that some of the changes had on their routine:

I had to change out of routine everyday at the bed \& breakfast. Every day was different so I had to wait and see what my tasks were going to be for the day. I embraced the change well. I always did the tasks I needed to do that day. (Intern C)

Time \& travel was a big break from the routine. I had to adjust to a 9-hour workday and a daily schedule. My entire lifestyle changed due to the internship. "J" (the manager) put me on the spot to learn things that I was most uncomfortable with. I needed a little nudge. I was really challenged at times. This was an "awareness" internship. (Intern B)

This internship made some changes in my life style and personal life because I got a lot of friends who are not Japanese. It changed my thinking about the city, confirmed my career choice. The internship did not change my thinking about my job in the future, but it changed my thinking about Cape, because I wanted to leave here as soon as possible before. (Intern F)

It was interesting to hear how the interns summarized their internship and the interactions and situations that were most helpful to their learning experience. Intern B put it simply: "Self-motivation has helped me learn a lot of what I learned." Some of the interns acknowledged that the learning experience had some negative moments 
and some of them struggled with their new responsibilities. Overall, the interns

expressed gratitude and appreciation regarding their internship opportunity. Some of

the ways interns summed up what was most helpful to their learning experience is as

follows:

Even though there are some negative things about this internship it is all right because there are a lot of positive things too. I am learning a lot about hospitality. I feel like I'm getting a well rounded experience in many areas. (Intern C)

The most helpful thing to me in learning new skills at my internship has been the hands on learning experience. It provided me with the opportunity to put what I was learning into practice as I was learning it. The hands on learning additionally helped me remember how each position was supposed to be done because I repeatedly performed each action numerous times before I learned a new spot. (Intern D)

At $\mathrm{AB}$ I was thrown into the position, I didn't have a chance to learn why I was doing it one way or another. At $\mathrm{C}$ my supervisor was more of a teacher. I am thankful for both opportunities because they both taught me valuable lessons. At $\mathrm{AB} I$ learned by doing and at $\mathrm{CI}$ learned why. Another thing that I learned is always ask for a demonstration or how they would like things done. Chef D had joked that he could pick out people who went to culinary school and those who didn't just by asking them to make bread. He said the culinary graduates would all make similar standard dough while the one who had not attended a culinary school would ask what kind of bread to make. After that discussion I promised myself to always ask. (Intern E)

I learned a lot of things through the internship. I think that the most important thing is to be with a smile anytime to everyone, not only to the customers. I think that the workers' communication with smiles makes for a good atmosphere (in) the restaurant, and it may make customers more comfortable. (Intern F)

Intern $\mathrm{D}$ also highlighted what she discovered about herself during the internship and how thankful she was to have had the opportunity. She mentions the hesitation she had about being away from home to complete her internship:

I am thankful that I did my internship at the (major amusement park). It provided me with many experiences both good and bad. While working here, I learned more about myself and what I am capable of accomplishing. I also made many fantastic friends and memories 
that will stay with me for the rest of my life. I honestly do not think I would trade this experience for anything in the world. I was hesitant about being so far away from home, but I have definitely proven both to myself along with my family and friends that I am fully capable of taking care of myself while working for one of the most well-known employers in the world, a mouse.

While one intern expressed the gratitude she felt in learning from two different managers in a way that enhance her learning, Intern A commented on how she did not feel that her two managers spent enough time explaining the tasks involved in the job and why things were done the way they were. She rationalizes the process as follows:

I felt like A \& J (the managers) didn't take enough time to explain what all they were doing and why they were doing it. When I asked about what was the right way to deal with the receipts when making a "bundle" they said "Everyone does it their own way but this is how I do it." A \& J both did it differently. I suppose this is one of those examples where it is not as important as to how you come up with the answer, just as long as you do it correctly.

Intern $\mathrm{C}$ summarized her internship experience in a manner that may further support the ease of which she felt she adapted to the daily changes and sometimes negative situations that occurred:

I'm going to conclude this with lyrics from The Rolling Stones: "You can't always get what you want. You can't always get what you want. You can't always get what you want, but if you try sometimes well you just might find... You get what you need!" I feel like these lyrics kind of go a long with the internship and just life in general.

Intern B commented that she felt that she had new leadership skills upon completion of the internship, and she specifically identified the following skills and characteristics: "Patience, understanding, not anxious anymore, listening skills, constraint, and analytical" 
Intern $\mathrm{D}$ closed her comments by stating that she recognized the correlation between her hospitality management degree and the growth that she experienced during the internship:

I definitely feel more confident in myself. I was fairly confident before but now I have experience working in a position that correlates with the degree that I am earning. I have learned to trust my instincts more and not second guess myself over decisions I make regarding work. I have also figured out that I am willing to take more risks if I think they would have good outcome.

\section{Finding Five - The supervisors who submitted evaluations of the interns'} performance offered generally positive and encouraging comments about their leadership skill development and overall performance. All of the supervisors indicated that they would welcome more interns in the future from the hospitality management program at Southeast Missouri State University.

The comments reflect appreciation for the interns' contributions to the organization and observations about their strengths, as well as recommendations for future learning and development. The president \& CEO of one internship location stated the following:

It was a pleasure to have (Intern B) in the office. We attempted to expose her to as many aspects of our administrative procedure as possible, including but not limited to human resources, technology and the fiscal department. She also assisted me in planning for staff team-building exercises and interviewing workshop from a University of Alabama presenter. We appreciate the opportunity to have worked with her.

He also rated her performance as "excellent" in the following areas: Focus on customer service, ability to solve problems effectively, sales and marketing skills, ability to work as a team member, skill at building relationships, ability to handle stress or conflict and willingness to learn. 
The owner of an international cuisine restaurant rated Intern F as "excellent" in her overall performance. Her comments were as follows:

(Intern F's) performance while in (the restaurant) is superior. It is difficult for me to determine any area where she might need to improve. Her desire to learn more languages will prove to be a valuable asset and I hope she will continue to make professional improvement along with her versatility in being able to communicate globally through foreign languages and understanding of foreign cultures.

Her performance was evaluated in terms of her ability to communicate, provide customer service, solve problems effectively, ability to work on a team, ability to handle financial transactions and her willingness to learn. Her evaluation reflected the focus on those skills.

Intern $\mathrm{C}$ also received an evaluation reflecting an overall performance of "excellent". The owner of the bed \& breakfast commented:

She was the best intern I've ever had. She was a joy to have around and we really needed her. She followed instructions well and was open to doing whatever was necessary to make the guest experience a good one for the guests. I would suggest that she work on speaking up more. She was a little passive and didn't ask for things that she needed. I explained to her that she would have to learn to be more vocal about things and make sure that she speaks up for herself, be a little more assertive, if she wants to be in charge.

The evaluator's comments indicated that the interns were successful in achieving some level of skill development, particularly in those areas consistent with desired hospitality management leadership competencies.

Two of the supervisors provided a more balanced evaluation of the interns. The managing partner at the steakhouse where Intern A completed her internship rated her satisfactory in the ability to communicate effectively, time management skills, ability to solve problems, sales and marketing skills, skill at building relationships and willingness 
to learn. He rated her "above average" in her ability to work as a team member, ability to handle stress and conflict, ability to think strategically and her ability to address dissatisfied customers. He stated:

(Intern A) is very good at picking up systems and managing herself. She needs further education on entire management. I would recommend that she concentrate on people management as well as acquiring more experience in the back of the house.

His comments indicated that Intern A was evaluated on the skills that have been identified as the desired skills of hospitality professionals. However, he suggests that she continue to work on "people management", which would suggest that her interpersonal skills were still in need of development.

Intern $\mathrm{D}$ was evaluated on the company competencies by the supervisor at the major amusement park in Orlando, Florida. Her performance was rated on a scale of "Off Track, Falling Behind, and Right on Track, Moving Ahead or Leading the Way”. She was rated as "Right on Track" in the following areas: thinks strategically, inspires creativity and innovation, builds teams, builds relationships, communicates effectively, champions change, drives results, promotes workforce diversity and exhibits professional excellence. She was rated as "Moving Ahead" on delivering excellent service and demonstrating technical and functional competence. The supervisor's comments were as follows:

I have to thank (Intern D) very much for all of your hard work with us this past semester at (the park). From the start of your College Program, you were seen displaying the Service Four Keys of Safety, Courtesy, Show and Efficiency, and continued this momentum through the finish of your program. During this time you were there, you saw an attendance record breaking spring season at the busiest theme park in the world and could be counted on to have a smile on your face and to work well with your peers! However, some opportunities still exist for you to be more proactive in seeking out interactions with your leaders, as your 
somewhat shy demeanor prevented opportunities for some members of the team to truly get to know you. With all that being said, we have rated you will an overall "right on track" rating and can't wait to see you back and working with us in a seasonal capacity!

The evaluation provided some insight into the contributions made by the intern, areas for improvement, as well as what sounds like an open door to return to the company, at least as a seasonal employee.

\section{Summary}

The primary findings of this research were that the participants in this study were able to gain varying degrees of leadership and interpersonal competencies during their internship experience. The interns described numerous opportunities to develop their leadership competencies related to analytical, problem solving and financial skills and abilities. This finding is significant because these skills are aligned with future-oriented competency models for the hospitality management industry. All of the interns discussed their comfort and challenges in developing essential interpersonal skills such as team building, communication, and customer service and employee-relations. The interns described comfort in team situations and in developing positive employee relations, including friendships. They provided perspective on their supervisor's communication skills and how they gained an understanding of the value of interpersonal skills. The findings also indicated that marketing and technology skills were not gained by most of the interns. Those two skills, which have been identified as desired leadership competencies, where not enhanced by their internship experiences.

The interns also faced many challenges. They described their struggle with the amount of new knowledge that they had to learn and the changes required of their 
personal lives to adjust to the internship responsibilities. The majority of the internship supervisors stated that the interns were valuable to their organization and they ranked them moderate to high on achieving leadership skills, while acknowledging that more learning would be beneficial to their overall success. 


\section{Chapter V}

Analysis, Interpretation, Findings, Conclusions and Recommendations

The goal of this case study was to gain more knowledge regarding the relationship between experiential learning and the achievement of leadership competencies. This study explored the perceptions of six interns in a hospitality management internship program of the leadership competencies that they gained during their internship.

The researcher gained a better understanding of how the interns achieved the skills that are identified as management and leadership competencies for the hospitality industry. The researcher also gained insight into the perceptions of learning that occurs in the experiential learning environment and if students are able to integrate their classroom knowledge to the workplace, as well as validated the concept that the competency model is a beneficial tool that may help identify the KSAs that students are achieving and using during their internship. The researcher also gained knowledge on the perception of the interns' supervisor regarding their leadership and management skill development as well as their overall performance and growth during the internship.

This research used convenience sampling and case-study inquiry for data collection in the form of in-depth interviews and supporting data from documents in the form of journals, management-oriented assignments and critical-incident reports. The participants in this study were six undergraduate students completing their hospitality management internship at various hospitality-related locations in the U.S. The data was organized and analyzed by the broad categories that pertained to the research questions, 
then coded into subcategories by the themes and concepts that emerged. This research was based on the (6) research questions:

8. How do interns perceive their growth as a leader during their hospitality management internship experience?

9. What are the interns' perceptions of their communication skills?

10. What are the interns' perceptions of their interpersonal skills?

11. What are the interns' perceptions of their financial management skills?

12. What are the interns' perceptions of their information technology skills?

13. What are the interns' perceptions of their marketing skills?

14. What are the supervisor's perceptions of the leadership competencies and knowledge gained by interns during the internship experience?

These research questions were the basis for the categories that guided the study. Those categories were then used to code the data that provided subcategories for further analysis. The subcategories were based on the knowledge, skills and abilities aligned with the broader research questions. Horizonalization and cluster of meaning analysis was conducted on the various subcategories to allow the emerging themes and concepts that formed the findings.

The data used for this study included individual interviews and documents, which revealed the intern's perception of the knowledge, skills and abilities that they gained during their internship. The data also included the perceptions of their individual internship supervisor regarding their skill development and overall performance. The researcher used extensive quotes from the interns to allow the reader to reveal the 
personality and character of each intern and to accurately represent their experience and perceptions.

The previous chapter presented the five findings that emerged from this study. The findings were organized based on the overarching competencies of leadership, as well as the themes that emerged from the data. The purpose of this chapter is to provide interpretation and summation of the findings. This chapter will attempt to integrate the findings by providing three analytical subcategories that synthesizes the five findings into a more holistic analysis. Analytical Category I will present the leadership and interpersonal skills that emerged in Finding One, and the gap the interns discussed in achieving other leadership competencies from Finding Two. Analytical Category II will discuss the interpersonal competencies gained in Finding Three and the personal growth and adaptation to change that emerged in Finding Four. Analytical Category III will discuss the perceptions of the leadership skills achieved by the interns from the internship supervisors. The chapter will also address the assumptions made in chapter one and discuss how the findings may be similar to, or contradict, those assumptions. The chapter will conclude with a summary of the interpretation and findings and future recommendations for hospitality management stakeholders.

\section{Analytical Category 1: Gains and Gaps in Developing Hospitality Management Leadership Competencies.}

The primary finding of the study was that the majority of the interns found that they gained skills that are valuable leadership competencies for the hospitality industry. This finding is supported by five out of six interns indicating that they had the 
opportunity to gain problem solving, analytical and financial skills, which are core leadership competencies, based on future-oriented competency models. It appears that self-motivation played a role in keeping the interns focused on their goals. Four of the six interns mentioned that they were self-motivated, making statements such as:

"I'm easily self motivated" (Intern A); "I'm pretty good at self motivation" (Intern C); "I would say that I'm pretty self motivated" (Intern D); and "I've learned a lot about self motivation, pushing myself and learning that a great deal of hard work and passion can pay off" (Intern E).

Self-motivation likely played a role for the interns in maintaining passion and enthusiasm in their skill development. In discussing how they were able to achieve these skills, the interns identified the hands-on experiences and observations that allowed them to learn the competencies. Intern D stated: "The most helpful thing to me in learning new skills at my internship has been the hands on learning experience. It provided me the opportunity to put what I was learning into practice as I was learning it”. The majority of the interns had opportunities to build upon the specific leadership skills of problem solving, analytical and strategic thinking, and exposure to financial decisions within the range and scope of their internship position. The Sandwith (1993) Core Essential Competencies model identified several core essential competencies in the leadership domain. Those core essential competencies include; portraying enthusiasm, recognizing and solving customer problems, and managing customer problems with understanding and sensitivity (Solnet, Kralji, Kay \& DeVeau, 2009). The interns discussed the various factors that influenced how they recognized and solved customer-related problems: 
Intern D stated that "My problem solving skills have gotten better since moving down here (Florida) and Intern C commented: "I used problem solving skills when (the owners) were gone and I had to check-in guests and handle financial transactions - I had to figure out what to do".

The interns' exposure to analytical or strategic thinking opportunities appeared to be limited, in most cases, to customer-related situations. They discussed their experiences with learning to analyze a table/guest or when to make adjustments at the attraction to better accommodate guests. Some of the analytical skills that were gained were personally beneficial as well as customer related. Intern E commented; "I really improved my thinking in the kitchen by learning why things were done a certain way and using strategic thinking to improve my own production time".

Knowledge in financial management is considered a desirable skill for management and leadership success (Kay \& Moncarz, 2004). The specific competencies identified by Kay and Moncarz include planning and budgeting, having knowledge in financial and operational analyses, managing cash flow, and controlling costs. The interns discussed their observations and perceptions of the financial management situations that they encountered. Intern B worked with a budget and had the opportunity to make decisions regarding budget allocation. Interns $\mathrm{A}$ and $\mathrm{F}$ both worked with daily cash drawers at their perspective restaurants. Intern $\mathrm{C}$ managed financial transactions as well as had access to financial information for the bed and breakfast and made observations about the daily financial management. Intern A was able to closely watch the financial costs involved in a new business, as well as gain an understanding of the 
finances involved in a long-term successful operation. Although Intern D did not have the opportunity for first-hand or hands-on financial experience, it appears that she gained some financial awareness regarding employee wages. She stated: "I was really surprised that the coordinators from my attraction only make a dollar more than I do an hour. I would think that basically being in charge of an attraction they would make at least a few dollars more than I do". It seems that all of the interns had some exposure to the core financial competencies align with the desirable hospitality management leadership skills.

Kay and Moncarz (2004) also identified marketing and information technology as hospitality KSA's. Marketing skills include developing promotional and public relations strategies, using sales techniques, and establishing measurable and achievable goals. The information technology skills include using email and the Internet for resources and research, having knowledge in property management systems and operational application software. The second finding is that the majority of the interns cited lack of opportunities to develop technical and marketing skills. Though there were a few opportunities for exposure to these two areas, a gap remains between the depth and scope to which other leadership competencies were achieved.

Only one intern cited limited exposure to gain skill development in those two areas during her internship. Most of the interns described their exposure to technology as using simple devices such as cash registers and basic computer software such as Excel. Intern E commented that she "used a few machines and different equipment but I would not say my technology skills made a drastic improvement". Intern E completed her internship at a restaurant, which could possibly account for her limited us of information technology. However, similar comments were made by the interns who worked in other 
segments of the hospitality industry. The interns used social media, but their comments indicated that the organizations were using it sparingly or the managers were still developing that technical and marketing tool within the organization. In addition, opportunities to improve marketing skills were also limited. The interns identified situations where the marketing efforts were not as advanced as the situation might require. In most cases, the interns mentioned that they did not further develop these skills due to lack of exposure to these opportunities based on the job that they were assigned to do or that that their internship supervisor was not experienced enough at these skills to help them with this competency.

\section{Analytical Category 2: Interpersonal Skill Development and Personal Growth.}

All of the interns attempted to learn interpersonal skills and they appear to have gained some skills that are associated with interpersonal competencies. Four of the six interns discussed the challenges that they encountered with improving communication and interpersonal skills, which are fundamental competencies associated with leadership. The interns made observations about their manager's communication style that helped them understand how important it is for leaders to develop good interpersonal skills. Intern E stated; "at AB I witnessed the importance of management being able to communicate to one another". Intern D commented; "my interpersonal skills have changed. I tend to talk to people more often". The interns offered consistently affirmative responses when asked about the development of their communication skills. The

comments include: "I think that my communication skills did change during my internship"; "My communication skills have changed - I've gotten more patient as well 
as more outgoing"; and "I've learned to better communicate with the front of the house". Sandwith (1993) identifies interpersonal skills as a core essential competency, and those skills include face-to-face communication, oral communication, listening skills and ability to resolve conflicts.

The interns also spoke of their experience with team building and developing relationships with managers and coworkers. Building networks is a dimension of interpersonal skill development (Chung-Herrera, Enz and Lankau, 2003). The interns seemed to have developed team-building competencies when they commented that they worked well with teams, expressing comfort in their team situations. The interns provided examples of a few situations where they encountered challenges with a particular team member, though it doesn't appear that challenges with one member interfered with their ability to gain some development in team relationships.

The majority of the interns experienced personal growth and change in their lives during the internship. All of the interns indicated that their daily routines changed and that the internship required a significant adjustment to their lives. Sandwith identified adapting creatively to change as a leadership competency domain titled "creative". Adapting to change is identified as a core essential competency. Intern A commented that "Initially I thought that the change of routine would be difficult. I was hesitant at first but I like the new routine better". It appears as if adding more working hours to the day was an adjustment for most. The interns unlikely had previously worked the 40-hour week that is expected of them during the internship, which may have resulted in their comments about learning to embrace the long days. 
The basic premise of social learning theory is learning from, or being influenced by, observed behavior (Bandura, 1971). The social nature of the internship was likely to create friendships among the interns as they worked along side other interns or employees with similar skills and goals. Intern D commented that she had become really good friends with the other interns because "we can understand each other's frustrations with work". Intern F spoke about the "not all good but necessary" changes that she made and the new friends that helped her change her way of thinking about the city where she completed her studies and internship. She mentioned smiles and non-verbal cues as being important to establishing communication and comfort with each other. Her ability to communicate this way with fellow employees appeared to help her establish some friendships.

The interns also identified overall leadership competencies that they now see within themselves. At the start of the internship, each student offered the KSA's and characteristics that they identified with effective leaders. Upon completion of the internship, five of the six interns provided descriptors of the new KSA's and characteristics that they perceive they gained. Intern A felt that she was "more charismatic, more assertive, less timid, levelheaded, don't show my stress to customers, demonstrate managerial skills". The interns revealed that they were more patient, understanding, had improved listening skills, constraint, confidence, ability to delegate tasks and problem-solving skills. Though one intern perceived her manager as still learning leadership, with vision and better communication leadership was possible. The theme that appeared repeatedly with the interns was that a leader should lead by example than just commands. 


\section{Analytical Category 3: Supervisor's Perceptions and Evaluations.}

The perceptions of the supervisors of the interns corroborated that they indeed gained some knowledge, skills and abilities that are consistent with leadership and interpersonal skills. The majority of the supervisors rated the interns as "excellent" in areas related to problem-solving, analytical skill, financial skill, team-building, communications skills, and overall performance. The supervisors answered each question asked on the evaluation and offered additional comments and recommendations for learning. The supervisor for Intern F stated that her performance was "superior" and that she could not determine and area where she might need to improve. Intern F, in her comments about her own performance, stated that she had learned from her mistakes and identified areas where she had improved her performance, particularly in working with her team members and becoming more comfortable talking to customers. It may appear that the supervisor saw the improvements and not the challenges with this individual, although she did state that "I hope (Intern F) continues to make professional improvements along with her versatility in being able to communicate".

Two of the supervisors provided a more balanced evaluation, citing a more "satisfactory" performance and outlining areas that the interns might benefit from more development. The supervisors discussed their gratitude to the interns for their contributions to their perspective organizations, as well as highlighted areas for improvement, which were leadership and interpersonal in nature. The supervisor for Intern A rated her as "average" on the ability to solve problems effectively, skill in building relationships, communicate effectively and receive constructive criticism. He did, however, find her above average on strategic thinking, customer service skills and 
the ability to deliver quality and her knowledge of technology. Overall he provided her with an "average" performance rating.

The performance evaluation questions that the supervisors responded to are derived from competency models identified by the hospitality management industry. The questions regarding leadership and interpersonal skills, as well as areas for growth and future learning, provide the supervisors with an understanding of the skills and abilities that are being measured. Each intern was a different case within this study and as such, the perceptions of the supervisors regarding particular skills and abilities are likely to be influenced by the knowledge and skills required of their perspective industries and that intern. There may be variations of the value of analytical skill in one segment of the industry versus another. Demographic factors and prior experience of the intern may influence the overall performance evaluation as the supervisor may have varying expectations and job descriptions at each location dependent those factors.

The supervisors also overwhelmingly indicated that either the intern was welcomed back, or that they would welcome more interns in the future from the hospitality management program. There may be benefits for the hospitality management program in maintaining relationships with employers and internship supervisors in the hospitality industry. Future hospitality management students at Southeast Missouri State University may benefit from having access to experiential learning locations across various segments of the industry with a record of providing a valuable hands-on learning experience. This access may enhance recruitment efforts for students and new relationships for all stakeholders involved. 
The hospitality management program at Southeast Missouri State University may also benefit from the students newly acquired knowledge that may be used in the classroom. Morgan (2004) suggests that "regardless of the level of knowledge acquired by the student at their experiential learning placement, the placement experience will impact their classroom experience".

\section{Assumptions from Chapter One}

Several assumptions were presented at that start of this study and it may be beneficial to revisit those assumptions in light of the findings presented.

The first assumption was that the interns will be different upon completion of their internship than when they started the experience and that the interns would be individually changed. Professional development and personal growth would take place as a result of the learning loop that occurs that integrates knowledge, experience and reflection. The interns in this study expressed that they had gained new leadership and interpersonal skills desired in the hospitality industry. The interns described the new skills and abilities that they believe they gained upon completion of the internship, such as: improved communication skills, patience, analytical skills, and the ability to learn from mistakes, working knowledge of the product or service that they provided, and more self-awareness. The interns discussed the personal growth they gained including confidence and more personal relationships. They also commented on their opportunities to integrate their classroom knowledge with the hands-on experience they were receiving.

A second assumption of this study was that the supervisors at the internship location that participate in the supervision and evaluation of the intern are competent in 
their ability to evaluate the interns and provide relative feedback. The supervisors received the evaluation at the start of the student's internship and thus the researcher assumed that they were aware of the competencies that were being measured and were capable and qualified to supervise and evaluate the interns. The supervisors that were part of this study included owners of the individual businesses, a chief executive officer (CEO), executive chef, and front line managers. The researcher assumed that the supervisors had previous experience with supervising employees. The supervisor for Intern $\mathrm{D}$ provided her own evaluation form, which was the required form used by that organization for evaluating interns. The competencies measured on that performance evaluation were overall similar, or the same as, the competencies measured by all other supervisors.

\section{Summary of Interpretation \& Findings}

This chapter presented the perceptions of hospitality management interns and supervisors regarding the competencies achieved during an internship experience. In summary, the discussion illustrates the individual nature of leadership skill development yet the similarities that exist among each case, as well as how the process of leadership development varies across the hospitality industry. It provides an explanation as to what interns perceive to be leadership competencies, how they were able to develop those competencies, how they perceive the competencies that they didn't develop, how the internship process impacted their personal lives and the perception of their skill development as evaluated by their perspective supervisors. 
The objective of analyzing the findings was to produce a holistic and integrated framework for synthesizing the data, yet present the depth of the individual cases. Analyzing the findings was also conducted to make sense of the nuances and structural differences within each internship location and the personal factors that influenced each intern's skill development. In analyzing the data across each case, the researcher did not find any significant factors (demographic, interpersonal, and professional) that would explain the findings any differently.

When analyzing the findings in this study, the reader may want to consider a few factors. First, the sample used in this study was a convenience sample on six interns completing their required hospitality management internship. Second, the study focused primarily on a specific set of knowledge, skills and abilities (KSAs) commonly associated with hospitality management but did not analyze all of the possible competencies related to leadership as a whole. Third, analysis of findings does not address the question regarding the level of achievement of specific KSAs by one student compared to another. More research is needed to examine if the attainment of particular KSAs are predicated upon other factors, such as academic grade point average, personality traits, and other demographic information, which may further influence or impact individual perceptions of the experiential learning process. Therefore, it can be emphasized that the implications of this study are specific to the experiences of the six interns in this study and not to the perceptions of competencies achieved by all hospitality management interns. The researcher acknowledges that there may be bias involved in that the researcher is also a faculty member in the hospitality management program and the internship advisor. To that end, the researcher attempted to avoid any 
bias by remaining open-minded throughout the data collection and analysis process and aware that the analysis of these findings are specific only to the small group of interns that participated in this study.

Conclusions and Recommendations

The goal of this case study was to gain more knowledge regarding the relationship between experiential learning, or internships, and the achievement of leadership competencies. This study explored the perceptions of six interns in a hospitality management internship program of the leadership competencies that they gained during their internship. The conclusions of this study follow the research questions and the findings and address the following areas:

- Perceptions that leadership skills were gained in several areas but gaps remain

- Interpersonal skills were enhanced

- Personal growth and change occurred

- Supervisor perceptions were overall positive

Following is a discussion of the conclusions drawn from this study followed by the researcher's recommendations for this study.

\section{Perceptions that Leadership Skills were gained in several areas but Gaps Remain}

The first major finding of this study is that five of the six interns identified analytical, financial and problem solving competencies that they gained. A conclusion that can be drawn from this is that hands-on learning opportunities were available to 
develop these leadership skills. Their exposure to management situations allowed them to develop or enhance their analytical skills and learn some new financial realities and they were able to see the results of poor and good financial management. They were also provided opportunities to solve problems and find the solutions on their own. A related conclusion is that the internship positions that they held were structured to provide the intern with entry-level exposure to leadership skills and that they learned by trial and error with limited consequences for errors during their learning experience. Though not all leadership competencies were available to learn at the same level, the students were able to recognize those skills and address them within their degree of exposure.

It can also be concluded that there was little opportunity to gain marketing and technology skills. It appeared that these skills were utilized and developed more by the intern working in the lodging internship industry compared to the other internships. A further and related conclusion is that the locations did not require advanced technology due to various factors and the interns did not have positions that required those marketing and technology skills at their position level. A conclusion can be made that this does not imply these skills are not valuable to those organizations, but not emphasized during these particular experiences.

\section{Interpersonal Skills Were Gained}

The second major finding was that all of the interns enhanced their interpersonal skills. The interns demonstrated awareness of the importance of these skills by their supervisors and managers and were able to offer details regarding their 
exchanges with employees, conflicts and solutions associated with them and their increased confidence in these skills. The interns made references to previous working experiences that made them aware and slightly more comfortable with skills aligned with interpersonal competencies. A conclusion that can be drawn from this is that the interns were able to recognize these skills and their value, as well as their strengths and weaknesses regarding these skills. They spoke of having previous experience that may have helped them embrace team work as well as focus on communication skills that they perceive to be important. A related conclusion is that they were able to gain this skill adeptly and make larger gains due to their awareness and previous experience with these skills. Their critique of management may imply they are confident in their knowledge about the subject. Some of the interns indicated that they had seen some of the behavior before in other managers. A final conclusion that can be made is that the intern's comments regarding interpersonal skills indicate an ability to analyze behavior within the core of interpersonal skills, as several interns analyzed their communication skills and its impact on their team members.

\section{Personal Growth and Change}

The interns identified several factors that impacted their individual growth and development, yet there was some commonality between them. This study's fourth finding was that all of the interns expressed that they experienced personal growth at the end of their internship and gain some of the same leadership competencies that they identified at the beginning of their internship as being desirable leadership skills. The majority of them said that they had to adapt to the changes that the new internship 
required, such as longer days and minimal supervision. Most of them also stated that their motivation, hands-on experience, and their relationships helped guide them through their growth. Two conclusions can be drawn from this. The ability to adapt to change indicates that the internships are different than previous work experiences and that they were rigorous and demanding, requiring the interns to manage the change and new demands. All of the interns commented about this, which indicates that transitioning to a daily working life is an important step to exposing the interns to the realities of some of the demands of the hospitality industry. A second conclusion is that the hands-on experience that they participated in impacted their personal growth. The interns spoke reflectively about how the experience helped them learn new skills and despite bad times in their internship, they expressed gratitude for their experience. They were able to identify specific new competencies that they achieved at the conclusion of the internship.

\section{Supervisor Perceptions of Leadership Competencies}

The study's fifth finding was that the majority of the supervisors of the interns had a favorable perception of the interns regarding their leadership skill development. The primary conclusion that can be made from this is that the supervisors were overall satisfied with the interns' performance based on their ratings and comments. The supervisors rated the interns as satisfactory (3), above average (4) and excellent (5) on all of the same leadership and interpersonal skills. The supervisors were competent in their positions and were able to accurately and equitably rate the interns. A second conclusion from this finding is that learning opportunities sill remained for a couple of 
the intern's. The supervisors provided constructive comments about where the intern could benefit from more learning and appeared to have been aware of each intern's leadership and interpersonal abilities. Each supervisor also responded "yes" to the question of their willingness to supervisor future interns from the hospitality management program. A final conclusion can be made that the interns in this study have an overall performance that was satisfactory enough to warrant future interest in interns from the same hospitality management program. The performance of these interns appeared to reflect positively on the preparedness of the students for an internship.

\section{Recommendations}

The researcher offers recommendations based on the findings and conclusions of this study. The recommendations that follow are for:

- Hospitality Management Interns

- Hospitality Management Academic Program Internship Advisors and Faculty

- Hospitality Management Industry Internship Supervisors

- Recommendations for Future Research.

\section{Recommendations for Hospitality Management Interns}

There are several individual factors that can influence each intern's experience. Two factors that seemed to enhance the interns' experience were their previous work experience and having an understanding of the objectives and goals of the internship. The impact that the experiential learning had on the lives of the participants in this study 
may suggests that the more informed the intern is about the internship expectations, and the more experience they have with working and other life adjusting activities, the more apt they are to enhance their overall leadership skill development. One recommendation for consideration is that the hospitality management student gains work experience prior to the internship to provide more ease in adjusting to the demands of the internship and to enhance the overall experience. The researcher also recommends that the intern have an understanding of the goals and the objectives of the internship prior to starting so that they may be able to meet the expectations of the employer and identify their personal development and growth.

\section{Recommendations for Hospitality Management Internship Advisors and Faculty}

Faculty and advisors in hospitality management programs may consider several ways in which the findings and conclusions in this study may benefit their programs. The following should be considered:

- The interns highlighted their perceptions of the skills and competencies required of hospitality management professionals. They saw opportunities to integrate their classroom knowledge of KSAs into the internship experience. Hospitality management program advisors and faculty should consider ensuring that students have a fundamental knowledge of the KSAs that are desired by the industry and how to integrate their knowledge with the skills and abilities desired in the workplace, creating the learning loop that has been identified as beneficial in the experiential learning process. 
- Hospitality management program faculty and advisors should work with the industry professionals to form relationships that continue to provide access to internship opportunities and to assist in designing the competency and outcomes that align with the growth of the hospitality industry and academia.

\section{Recommendations for Hospitality Management Industry Internship Supervisors \\ Industry professionals that design and supervise students in hospitality management internships should:}

- Understand the scope of the hospitality management program and the courses that the interns are completing prior to their internship so that the supervisor can better design the internship that best suits the base of knowledge that the student has been exposed to.

- Have an understanding of the policies and procedures of the internship and how the interns fulfill the requirements.

- Have the ability to supervise the intern and provide constructive feedback for their leadership and management development.

- Maintain a relationship with hospitality management staff to ensure that the hospitality management organization has access to future managers and leaders through experiential learning to maintain their growth in the industry with qualified professionals. 


\section{Recommendations for Future Research}

This research should provide valuable insight into how hospitality management programs can prepare students as future leaders in the industry and help bridge the leadership deficit that exists. However, based on the limitations of this research, a study using a larger population across more diverse hospitality management programs would provide more data on the depth and range of leadership competencies that interns are gaining.

Further research should be done on graduates of hospitality management programs who completed internships to identify what type of management and leadership positions they hold and if the leadership and interpersonal skills that they gained are utilized in their current positions. Finally, more research may be beneficial for hospitality management programs that do no have experiential learning components in their curriculum. Identifying how other programs can implement the structural and philosophical changes that are required to incorporate an experiential learning program into the curriculum may be valuable. 


\section{REFERENCES}

American Hotel \& Lodging Association 2011 Lodging Industry Profile (2010 at a glance), 5/25/12).

Annaraud, K. (2006). A Comparison of Skills Necessary for Successful Careers for American and Russian Hospitality Students upon Graduation. Journal of Hospitality \& Tourism Education, 18 (4), 33-44.

Arendt, Susan W., \& Gregoire, Mary B. (2008). Reflection by Hospitality Management Students Improves Leadership Practice Scores. Journal of Hospitality \& Tourism Education, 20 (2), 10-15.

Bandura, Albert. (1971). Social Learning Theory. New York, NY: General Learning Press.

Barrows, C. \& Bosselman, R. (1999). Hospitality Management Education. Binghamton, NY: The Hawthorn Hospitality Press.

Billsberry, J. (2009). The Social Construction of Leadership Education. Journal of Leadership Education, 8: 1-9.

Bloomberg, L. \& Volpe, M. (2012). Completing your Qualitative Dissertation: A Road Map from Beginning to End. Thousand Oaks, CA: Sage Publications.

Bogdan, R.C., \& Biklen, S. K. (1982). Qualitative research for education: An introduction to theory and methods. Boston: Allyn and Bacon, Inc.

Bolman, L. \& Deal, T. (2008). Reframing Organizations: Artistry, Choice, and Leadership $\left(4^{\text {th }}\right.$ ed.). 10, 149-157. San Francisco: Jossey-Bass.

Brownell, Judi (2007). Leading on Land and Sea: Competencies and Context. International Journal of Hospitality Management. 27 (2008), 137-150.

Bruffee, K. (1999). Collaborative Learning: Higher Education, Interdependence, and the Authority of Knowledge ( $2^{\text {nd }}$ ed.). Baltimore: The John Hopkins University Press.

Butterfield, L.D., Borgen, W.A., Amundson, N.E., \& Maglio, A.T. (2005). Fifty Years of the Critical Incident Technique: 1954-2004 and Beyond. Qualitative Research, 5(4), 475-497.

Cannon, A.J. \& Arnold, M. J (1998). Student expectations of collegiate internship programs in business; a 10-year update. Journal of Education for Business 73(4), 202-205. 
Chung-Herrara, B., Enz, C. and Lankau, M. (2003). Grooming Future Hospitality Leaders: A Competency Model. Cornell Hotel and Restaurant Administration Quarterly, June, 2003, $17-25$.

Clark, J. and Webb White, G. (2010, February). Experiential Learning: A Definitive Edge in the Job Market. American Journal of Business Education 3, 2, 115-118.

Clark, R.A., Hartline, M.D., and Jones, K.C., (2009, May). The Effects of Leadership Style on Hotel Employees' Commitment to Service Quality. Cornell Hospitality Quarterly, $50(2), 209-231$.

Cook, S., Parker, R., Pettijohn, C., (2004). The perception of interns: A longitudinal case study. Journal of Education for Business, 79 (3), 179-186.

Creswell, J.W. (2007). Research and Evaluation in Education and Psychology:

Integrating Diversity with Quantitative, Qualitative, and Mixed Methods ( $2^{\text {nd }} \mathrm{ed}$.). Thousands Oaks, CA: Sage Publications.

Crosbie, R. (2005). Learning the Soft Skills of Leadership. Industrial and Commercial Training, 37(1), 45-51.

Dewey, J. (1938). Experience and Education. New York: Collier Books.

Drucker, P. (1968). The Age of Discontinuity. New York: Harper \& Row, p. 264.

Duke, C. (2002). Learning Outcomes: Comparing Student Perceptions of Skill Level and Importance. Journal of Marketing Education, 24(3), 203-217.

Eraut, Michael (2004, July). Informal Learning in the Workplace. Studies in Continuing Education, 26(2), 247-273.

Eyler, J. (2009). The Power of Experiential Education. Liberal Education, 95(4), 24-31.

Fink, A. (2009). How to Conduct Surveys: A Step-by-Step Guide, $4^{\text {th }}$ ed. Thousand Oaks, CA: Sage Publications.

Ford, J., Lawler, J. (2007) Blending existentialist and constructionist approaches in leadership studies: An exploratory account. Leadership \& Organization Development Journal, 28(5), 409 - 425

Furst-Bowe, J.A. \& Wentz, M. (2006). Beyond Baldrige. University Business. 9(9), 45 48.

Gault, J., Redington, J., \& Schlager, T. (2000). Undergraduate business internships and career success: Are they ready? Journal of Marketing Education, 22(1), 45-53. 
Gentry, J. W. (1990). What is experiential learning? Guide to Business Gaming and Experiential Learning, 9-29.

George, R. (1999). Toward a constructivist framework for guiding change and innovation in higher education. Journal of Higher Education, 70 (3), 235-236.

Getty, J.M, Tas, R. E., \& Getty, R.L. (1991). Quality assessment of hotel and restaurant management graduates: Are we meeting our mission? Hospitality Research Journal, 14 (2), 393-403.

Gill, Stephen (2010). Developing a Learning Culture in Nonprofit Organizations. Thousand Oaks, CA: Sage.

Gregoire, M. B. (2010). Foodservice Organizations: A Managerial and Systems Approach ( $8^{\text {th }}$ ed.). Saddle River, N.J: Pearson.

Grint, K. (2000). The Arts of Leadership. Oxford: Oxford University Press.

Groenewald, T. (2004, April). A Phenomenological Research Design Illustrated. International Journal of Qualitative Research, 3(1), 1-26.

Hedrick, T.E., Bickman, L., \& Rog, D. (1993). Applied Research Design: A Practical Guide. Newbury Park, CA: Sage Publications.

Hite, R. \& Bellizzi, J. (1986). Student expectations regarding collegiate internship programs in marketing. Journal of Marketing Education 8 (3), 41-49.

Hoepfl, M. (1997). Choosing Qualitative Research: A Primer for Technology Education Research. Journal of Technology Education. 9 (1), 47-55.

Hoover, D. \& Whitehead, C. (1975). An Experiential-Cognitive Methodology in the First Course in Management: Some Preliminary Results. Simulation Games and Experiential Learning in Action, 2, 23-25.

Hoover, J. Duane and Carlton Whitehead (1975), “An Experiential-Cognitive. Methodology in the First Course in Management: Some Preliminary Results". Simulation Games and Experiential Learning in Action, Richard H. Buskirk (ed.), 25- 30 .

Jenning, C. \& Wargnier, J. (2010). Experiential learning - a way to develop agile minds in the knowledge economy? Development and Learning in Organizations. 24 (3), 14-16.

Johanson, M., Ghiselli, R., Shea, L., and Roberts, C. (2011). Changing Competencies of Hospitality Leaders: A 25-Year Review. Journal of Hospitality \& Tourism Education, 23(2), 43-47 
$\mathrm{Ju}, \mathrm{J}$. (1997). Korean students' perceptions of the effectiveness of their internship experiences in the hospitality industry in Korea. (UMI No. 1385983)

Katz, R. L. (1974). Skills of an effective administrator. Harvard Business Review, 52(5), 90-102.

Kay, Christine \& Moncarz, Elisa (2004). Knowledge, Skills, and Abilities for Lodging Management. Cornell Hotel and Restaurant Administration Quarterly. 45(3), 285298.

Kay, Christine \& Russette, John (2000, April). Hospitality Management Competencies: Identifying Managers' Essential Skills. Cornell Hotel and Restaurant Quarterly. (41), $52-63$

King, B. (1994). Co-operative education for hospitality and tourism students: An Australian case study. Australian Journal of Hospitality Management, 1(2), 53-70.

Kolb, D. (1984). Experiential Learning: Experience as the Source of Learning and Development. Englewood Cliffs, New Jersey: Prentice Hall.

Koppel, J.N. (1976). The field experience in hospitality management. The Journal of Hospitality Education, 1(1), 6-19.

Lam \& Ching (2006) in Lee, S. \& Dickson, D. increasing student learning in the classroom through experiential learning programs outside the classroom. Journal of Hospitality \& Tourism Education. (2010). 22 (3) 27-34

Lee, S. (2007). Increasing Student Learning: A Comparison of Student's Perceptions of Learning in the Classroom Environment and their Industry-Based Experiential Learning Assignments. Journal of Teaching in Travel \& Tourism. 7 (4), 37-54.

Lee, S. \& Dickson, D. (2010). Increasing Student Learning through Experiential Learning Programs outside the Classroom. Journal of Hospitality \& Tourism Education, 22 (3), 27-34.

Lee, Seoki and Kamp, Harvey (2005). Learning-styles of Hospitality Students: Do Career Interest Make Differences in Learning-styles? Journal of Hospitality \& Tourism Education. 17(3), 2733.

Lincoln, Y.S. \& Guba, E.G. (2000). Paradigmatic Controversies, Contradictions, and Emerging Confluences. In N.K. Denzin \& Y.S. Lincoln (Eds.), Handbook of Qualitative Research (2 $2^{\text {nd }}$ ed., pp.163-168). Thousand Oaks, CA: Sage. 
Mau, W.C. \& Fernandes, A. (2001). Characteristics and satisfaction of students who used career counseling services. Journal of College Student Development, 42 (6), 581588.

Maxwell, C. I. \& Greenhalgh, A.M. (2011). Images of Leadership: A New Exercise to Teach Leadership from a Social Constructionist Perspective. Organization Management Journal (8), 106-110.

Merriam, S. B. (1998). Qualitative Research and Case Study Applications in Education. San Francisco, CA: Jossey Bass. (p. 44-49)

Mertens, D.M. (2005) Research and Evaluation in Education and Psychology: Integrating Diversity with Quantitative, Qualitative, and Mixed Methods ( $2^{\text {nd }} \mathrm{ed}$.). Thousand Oaks, CA: Sage Publications.

Moore, D. T. (2004). Curriculum at Work: An Educational Perspective on the Workplace as a Learning Environment. Journal of Workplace Learning, 16, 325-340.

Moore, D. T. (2007). Analyzing Learning at Work: An Interdisciplinary Framework. Published On-line: 1 August 2007: Springer Science and Business Media, LLC. pp. $175-188$.

Morgan, M. (2004). From Production Line to Drama School: Higher Education for the Future of Tourism. International Journal of Contemporary Hospitality Management, 19(2), 91-99.

National Association of Colleges and Employers (NACE). (April, 2010) Spotlight Online for Career Services Professionals. Retrieved August 14, 2011, from http://www.naceweb.org/Publications/Spotlight_Online/2010/0428/Internship_Pro grams

Nelson, A.A. (1994). Hospitality internships: The effects of job dimensions and supportive relationships on student satisfaction. (Doctoral dissertation, Wayne State University, 1994). Doctoral Abstracts International, 56 (02), 626.

Nonaka, I. (1991). The Knowledge Creating Company. Harvard Business Review, November-December, 96-104.

Parker, D.L., Webb, J., \& D’Souza, B. (1995, April). The Value of Critical Incident Analysis as an Educational Tool and its Relationship to Experiential Learning. Nurse Education Today, 15 (2): 111-6.

Patton, M. Q. (1990). Qualitative Evaluation and Research Methods (2nd ed.). Newbury Park, CA: Sage Publications, Inc. 
Patton, M. Q. (2002). Qualitative Research and Evaluation Methods, $4^{\text {th }}$ ed. Thousand Oaks, CA: Sage Publications.

Pavesic, D. (1991). Pragmatic Issues in Undergraduate Hospitality Education. Hospitality \& Tourism Educator, 3(2), 38-51

Perry, P. (1989, July 17). Firms want more from marketing schools. Marketing News Magazine, pp1-2.

Polkinghorne, D.E. (1983). Methodology for the Human Sciences: Systems of Inquiry. Albany: State of New York University Press.

Raymond, M.A. \& McNabb, D.E (1993). Preparing graduates for the workforce: The role of business education. Journal of Business Education, 68 (4), 202-206.

Rost, J. C. (1991). Leadership for the Twenty-First Century. Westport, CT: Greenwood.

Saldana, J. (2009). The Coding Manual for Qualitative Researchers. Thousand Oaks, CA: Sage Publications.

Sandwith, P.(1993). in Solnet, D., Kralj, A., Kay, Christine, \& DeVeau, L., (2009). A Lodging Internship Competency Model: Enhancing Educational Outcomes through Work Integrated Learning. Journal of Hospitality \& Tourism Education, 21, (4), 16-23.

Simmons, J. C. (2006). Hospitality Internships as a career development tool: Stakeholder Perceptions and Expectations. (Doctoral Dissertation, Auburn University, 2006). UMI No. 3253141.

Simon, R. I, Dippo, D., \& Schenke, A. (1991). Learning Work: A Critical Pedogagoy of Work Education. New York: Bergin \& Garvey

Solnet, D., Kralj, A., Kay, Christine, \& DeVeau, L., (2009). A Lodging Internship Competency Model: Enhancing Educational Outcomes through Work Integrated Learning. Journal of Hospitality \& Tourism Education, 21, (4), 16-23.

Strauss, A \& Corbin, J. (1990). Basics of Qualitative Research: Grounded Theory Procedures and Techniques, $2^{\text {nd }}$ ed. Sage Publications, Inc.

Tas, R.F. (1998). Teaching future managers. The Cornell Restaurant Administration Quarterly, 29(2), 41-43.

Tesone, D. (2004, November 6). Whole Brain Leadership Development for Hospitality Managers. International Journal of Contemporary Hospitality Management, 16, 363-368. 
Thiel, G. R. \& Hartley, N.T. (1997). Cooperative education: A natural synergy between business and academia. SAM Advanced Management Journal, 62(3), 19-24.

Tobias, A.J. (1996). Co-op Programs a Good Deal All Around. Electronic Engineering Times, (1996, September 30), p. 142.

Umbreit, W.T. (1993). Essential Skills: What graduates need to succeed. Hosteur, 3 (1), 10-12.

Wilson (1988) as found in Lee, S. \& Dickson, D. (2010). Increasing Student Learning through Experiential Learning Programs outside the Classroom. Journal of Hospitality \& Tourism Education, 22 (3), 27.

World Travel \& Tourism Council, Economic Impact Outlook 2012, http:// www.wttc.org, $5 / 25 / 12$

Young, Cheri A., \& Lundberg, Craig C. (1996). Creating a Good First Day on the Job. Cornell Hotel and Restaurant Administration Quarterly. (37), 6, 26-33.

Yukl, G. (2006). Leadership in Organizations, ( $7^{\text {th }}$ Ed.). Upper Saddle River, N.J.: Prentice Hall

Zopiatis, A. (2007). Hospitality Internships in Cyprus: A Genuine Academic Experience or a Continuing Frustration? International Journal of Contemporary Hospitality Management, 19(1), 65-77.

Zopiatis, A. and Constanti, P. (2012). Managing Hospitality Internship Practices: A Conceptual Framework. Journal of Hospitality \& Tourism Education, 24 (1), 44-50.

Zwaal, W. and Otting, H. (2007). Hospitality Management Students' Conceptions of Education. Tourism and Hospitality Research, 7, 256-268. 
APPENDICES 


\section{APPENDIX A}

\section{Institutional Review Board (IRB) Authorization Agreement}

Name of Institution or Organization Providing IRB Review (Institution A):

Name southeast Missouri State University

Address One University Plaza, MS\# 3000, Cape Girandeau, MO 63701

IRB Registration \#: 00009223

Assurance (FWA) \#: FWA00019886

Name of Institution or Organization Relying on the Designated IRB (Institution B):

Name: University of Missouri-Columbia

Address: 485 McReynolds Hall, Columbia, MO 65211

IRB Registration \#: 00000660

Assurance (FWA) \#: 00002876

The Officials signing below agree that the University of Missouri-Columbia may rely on the designated IRB for review and continuing oversight of its human subject research described below: (check one)

(..) This agreement applies to all human subject research covered by Institution B's FWA.

(X) This agreement is limited to the following specific protocol(s):

Title of Research Project: Experiential Learning in Hospitality Management: An Exploration of the Knowledge, Skills, and Abilities Achieved in a Hospitality Management Internship Program

Name of Principal Investigator: Quantella M Anderson-Noto

IRB Project Number: $11-001$

Name of Sponsor or Funding Agency:

Sponsor or Funding Award Number:

Other (describe):

The review performed by the designated IRB will meet the human subjects protection requirements of Institution B's OHRP-approved FWA. The IRB at Institution A will follow written procedures for reporting its findings and actions to appropriate officials at Institution $B$. Relevant minutes of IRB meetings will be made available to lnstitution $B$ upon request. Institution $B$ remains responsible for ensuring compliance with the IRB's determinations and with the terms of its OHRP-approved Assurance. This document must be kept on file at both institutions and provided to OHRP upon request.

Signature of Signatory Official (Institution A): 2 etlly

NOTE: The IRB of Institution A must be designated on the OHRP-Approved FWA for Institution B.

Signature of Signatory Official (Institution B): luclule fennett Date: $2 / 28 / 2013$

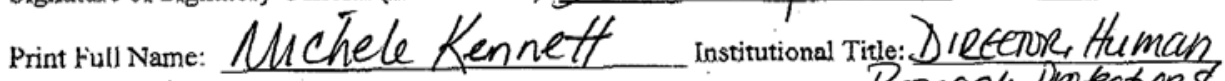
Reseach protechons? 
APPENDIX B

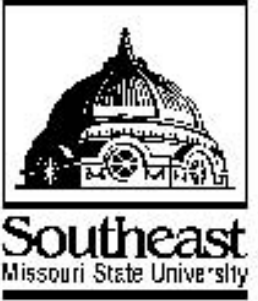

\author{
COLLEGE OF HEALTH AND HUMAN SERVICES \\ OFFICE OF THE DEAN \\ Crisp Hall 132 \\ Mail Stop 8000 \\ dbruns@semo.edu \\ Phone (573) 651-2178 \\ Fax (573) 651-5113
}

\title{
MEMORANDUM
}

TO: Quantella Anderson-Noto

FROM: Diana Bruns, Interim Dean / A s - $/ 4$.

College of Health and Human Services

DATE: $\quad$ February 28, 2013

SUBJECT: Experiential Learning in Hospitality Management: An Exploration of the Knowledge, Skills, and Abilities in a Hospitality Management Internship.

This memorandum is your official authorization to proceed with the study named above, after a human subjects review by the College review Committee (CRC). The CRC and I agree that this is a Category 1 project, meaning that subjects have no more than ordinary risk, by involvement in the study.

Your proposal number is 2013-032, which means that your proposal is the 32nd approval for 2012-2013. Your approval will expire three years from the date of this approval letter, or on February 28, 2016.

I appreciate your efforts in this scholarly work.

c: University Committee Chairperson

Dr. Shelba Branscum

Dr. Marcia Haims

Experience Southeast...Experience Success 
APPENDIX C

\section{INFORMED CONSENT FORM}

Title of Project: Experiential Learning in Hospitality Management: An Exploration of the Knowledge, Skills, and Abilities Achieved in a Hospitality Management Program Internship.

Investigator: Quantella Anderson-Noto

Department: Hospitality Management Program / Human Environmental Studies

Phone number: 573-986-6856

The purpose of this project is:

The goal of this research is to gain more knowledge of the relationship between experiential learning and the achievement of leadership competencies in a hospitality management internship. This study will address the following questions: 1.How do interns perceive their growth as a leader during the internship experience and 2. What are the supervisor's perceptions of the leadership competencies and knowledge gained by interns during the internship experience?

I understand that, as part of this project, I will:

Participate in the hospitality management program internship (FN473) and allow the researcher to use my personal academic data listed below for analyses:

1. Tri-Weekly Reports

2. Competency Assessment

3. Intern Interview - Interview Protocol Questions

4. A Critical Incident Report

5. Self-Reflection

6. Internship Supervisor Evaluation 
I understand that the risks associated with this procedure include:

Participation in this study is not expected to cause any risk greater than those encountered in everyday life. There are no adverse consequences (physical, social, economic, legal or psychological) of a student's decision to withdraw from the research at any time. In the event of withdrawal, the student will continue their internship requirement but their data will not be used for the purpose of this study.

I understand that my participation is voluntary; I may refuse to participate and/or discontinue my participation at any time without penalty or prejudice. I understand that my participation or lack thereof will in no way affect my grade in the course (FN473 Hospitality Management Internship).

I understand that all information collected in this project will be held confidential. The student's identity and participation will remain confidential. Individual names or information about the student will not be provided to anyone outside of the authorized research team. The raw data will be filed and stored in a locked file cabinet at the main research site (Southeast Missouri State University). Only the researcher will have access to the file and the data will be protected from unauthorized individuals. All records created thereof will remain solely with the researcher and only the researcher will have access to the records. Upon completion of the research, the data will not be destroyed but will remain with the researcher in a locked and protected location. In the event that the dissertation that utilizes this research is published, the researcher ensures continued confidentiality of identity and data.

I understand that by agreeing to participate in this project and signing this form, I have not waived any of my legal rights.

I understand that any questions or concerns I have will be addressed by the above named investigator. If I have further questions, I may contact the chairperson of the Human Subjects' Committee, Dr. Marcia Brown-Haims at 573-651-2188.

Signature

Student ID\#

Date 
Quantella Anderson-Noto was born August 5, 1961, in Cleveland, Ohio. She is one of six girls born in the family. She is Assistant Professor / Director of the Hospitality Management Program at Southeast Missouri State University, Cape Girardeau, MO. She is married with two sons. She currently resides in Cape Girardeau, MO.

Ms. Anderson-Noto graduated Cum Laude from East Stroudsburg University with a Bachelor of Science degree in Hotel, Restaurant and Tourism Management. She received her Masters of Tourism Administration from the George Washington University School of Business in Washington D.C, and a Doctorate in Educational Leadership and Policy Analysis from the University of Missouri-Columbia, Columbia, MO.

Prior to joining Southeast Missouri State, she served as an Instructor at Strafford University, Falls Church, VA, in the Culinary Arts and Hospitality Management department. She has held several positions in the lodging and foodservice industry, including operations, sales and catering positions.

Prior to joining the hospitality industry and academia, Ms. Anderson-Noto had a career in the banking and securities industry. Ms. Anderson-Noto also holds executive and supporting positions, and maintains membership in, numerous service, business, and hospitality-related organizations. 